\title{
Contingent Behavior and Asymmetric Preferences for Baltic Sea Coastal Recreation
}

\author{
Christine Bertram ${ }^{1} \cdot$ Heini Ahtiainen ${ }^{2}$ Jürgen Meyerhoff ${ }^{1,3}$ (D) Kristine Pakalniete ${ }^{4}$. \\ Eija Pouta ${ }^{2} \cdot$ Katrin Rehdanz ${ }^{1,5}$
}

Accepted: 19 November 2019 / Published online: 19 December 2019

(C) The Author(s) 2019

\begin{abstract}
In this study, we augment the traditional travel cost approach with contingent behavior data for coastal recreation. The objective is to analyze the welfare implications of future changes in the conditions of the Baltic Sea due to climate change and eutrophication. Adding to the literature, we assess the symmetricity of welfare effects caused by improvements and deteriorations in environmental conditions for a set of quality attributes. Responses are derived from identical online surveys in Finland, Germany and Latvia. We estimate recreational benefits using linear and non-linear negative binomial random-effects models. The calculated annual consumer surpluses are considerably influenced by the magnitude of the environmental changes in the three countries. We also observe asymmetries in the effects of environmental improvements and deteriorations on the expected number of visits. In particular, the results indicate that deteriorations lead to larger or more significant impacts than improvements in the case of blue-green algal blooms and algae onshore for Finland, water clarity for Germany, and water clarity and blue-green algal blooms for Latvia. For the remaining attributes, the effects are ambiguous.
\end{abstract}

Keywords Baltic Sea $\cdot$ Recreational benefits - Valuation - Contingent behavior · Eutrophication · Climate change $\cdot$ Water quality $\cdot$ Asymmetric preferences

JEL Classification Q26· Q51

Electronic supplementary material The online version of this article (https://doi.org/10.1007/s1064 0-019-00388-x) contains supplementary material, which is available to authorized users.

Christine Bertram

christine.bertram@ifw-kiel.de

1 Kiel Institute for the World Economy (IfW), Kiellinie 66, 24105 Kiel, Germany

2 Natural Resources Institute Finland (Luke), Helsinki, Finland

3 Technische Universität (TU) Berlin, Berlin, Germany

4 AktiiVS Ltd, Riga, Latvia

5 Kiel University, Kiel, Germany 


\section{Introduction}

The Baltic Sea provides many ecosystem services for the citizens of the riparian countries. These services are, however, threatened by continuing degradation of the environment and impacted by eutrophication and coastal erosion, among others. Consequently, policies such as the EU Marine Strategy Framework Directive (MSFD; EU 2008) have been put in place to sustain and improve environmental conditions. However, the effectiveness of measures is disputed and future developments remain unclear. In this nexus of impacts, environmental responses, and policy measures, it is important to evaluate how the citizens of the riparian countries might be affected by changing environmental conditions.

In this paper, we focus on the question of how potential future changes in environmental conditions affect the recreational benefits provided by the Baltic Sea. We employ the contingent behavior (CB) method for valuing their potential changes due to improvements and deteriorations in environmental conditions in three riparian countries of the Baltic Sea (Finland, Germany, and Latvia). The CB method is an extension of the travel cost (TC) method, employed predominantly to determine the recreational benefits of natural sites. While the TC method is restricted to valuing recreational benefits under current conditions, the CB method allows evaluating changes outside of the range observed today (Eiswerth et al. 2000; Englin and Cameron 1996). The CB method builds on reported recreational behavior in the past and future recreational behavior contingent on scenarios of varying environmental conditions. Consequently, it combines revealed and stated preference techniques employed in environmental economics to evaluate the welfare impacts of environmental changes.

There are numerous stated preference valuation studies on water quality, also in the context of the Baltic Sea (e.g., Nieminen et al. 2019; Pakalniete et al. 2017; Ahtiainen et al. 2014; Kosenius 2010). However, there are fewer revealed preference studies for valuing water quality changes (Czajkowski et al. 2015) and the number of CB studies is limited, in particular in the context of water quality changes with only one study referring to the Baltic Sea (Lankia et al. 2019). Existing CB studies focus mostly on other decision contexts than changes in marine water quality, such as changing access to recreation sites (Barry et al. 2011; Rolfe and Dyack 2011), water levels (Eiswerth et al. 2000), catch rates (Alberini et al. 2007), and reef quality (Kragt et al. 2009, Bhat 2003). Moreover, they mostly rely on on-site sampling for single sites and account for changes of only one environmental attribute in the CB scenarios (e.g., Barry et al. 2011; Rolfe and Dyack 2011; Kragt et al. 2009). Exceptions are Hanley et al. (2003) and Lankia et al. (2019). While the former study investigates the effects of bacteriological contamination along Scotland's south-west coast, the latter focuses on swimming activities in Finland using water clarity and sliminess as indicators for water quality. In both studies, several sites are pooled and treated as one generic site. If several sites are pooled, the reference environmental quality, i.e., the status quo (SQ), is likely to differ between recreation sites. ${ }^{1}$ However, information on the SQ at the visited site is a prerequisite to

\footnotetext{
1 Although uniform SQ alternatives provided to the respondents are more common in valuation studies, some stated preference studies employ individual-specific SQ alternatives (e.g., Ahtiainen et al. 2015; Glenk 2011; Masiero and Hensher 2010; Birol et al. 2009; Hess et al. 2008; Banzhaf et al. 2001). Few studies also examine the effect of provided and perceived SQ alternatives on welfare estimates in stated preference (Domínguez-Torreiro and Soliño 2011; Marsh et al. 2011) and revealed preference settings (Baranzini et al. 2010; Jeon et al. 2005; Adamowicz et al. 1997), finding differences in the welfare estimates between the formats.
} 
value environmental changes. Both Hanley et al. (2003) and Lankia et al. (2019) use perception data, i.e., the respondent's own assessment of the current environmental state, to construct the SQ quality, which is then individual-specific.

We extend this literature in at least three directions. First, we examine preference asymmetries for improvements and deteriorations of environmental quality in the $\mathrm{CB}$ setting. In previous CB studies, only Lankia et al. (2019) have examined asymmetric preferences. However, they only had two water quality attributes which were combined into a single variable with three levels (poor, intermediate, and good) in the analysis. They did not find asymmetric preferences for improvements and deteriorations for the combined variable. In the choice experiment literature, a few studies have incorporated individual-specific SQs and asymmetric modeling (Ahtiainen et al. 2015; Glenk 2011; Masiero and Hensher 2010; Lanz et al. 2010; Hess et al. 2008), finding consistent evidence of asymmetric preferences. We build on this literature and assess the relative importance of five environmental attributes (water clarity, blue-green algal blooms, algae onshore, number of bird, plant, and fish species, and facilities at the site) taking asymmetric effects of improvements and deteriorations of the individual attributes into account. This has, to the best of our knowledge, not been emphasized and analyzed in such detail before in revealed preference studies.

Second, pooling several sites in a TC or CB analysis implies that the visited site needs to be specified by the respondents. In earlier TC or CB studies pooling several sites, respondents only provided information about the perceived quality of a site without locating it explicitly (e.g., Lankia et al. 2019). Other studies use the postal code of the area where the recreational visit took place to locate the site (Czajkowski et al. 2015), which is associated with uncertainties about the exact location of the site. Hanley et al. (2003) use the names of the beaches to specify the visited sites, which is feasible only due to the relatively small number of beaches considered in the study. Overall, there is a tendency in former pooled TC and CB studies that the spatial location of the recreation site is only coarsely defined. We used specific survey software called Maptionnaire with an integrated mapping tool for collecting the survey data. This allowed our respondents to interactively specify their residence and recreation sites directly on an online map, which enabled us to determine distances between the place of residence and recreation sites.

Finally, although there are a number of valuation studies for the Baltic Sea area, these are mostly stated preference studies (for recent reviews see Sagebiel et al. 2016 and Bertram and Rehdanz 2013). Considering revealed preference studies, there is only one recent TC study in the context of the Baltic Sea area (Czajkowski et al. 2015); earlier TC studies include Vesterinen et al. (2010), Soutukorva (2005), and Söderqvist et al. (2005). We extend this literature by estimating recreational benefits provided by the Baltic Sea based on the CB method. This allows us to evaluate changes in environmental conditions beyond the observed state in a revealed preference setting. We do so by providing estimates of recreational benefits separately for three riparian countries of the Baltic Sea, namely for Finland, Germany, and Latvia, which also allows for country-wide comparisons of recreational behavior.

The remainder of the paper is structured as follows. In Sect. 2, we describe the data and study design including survey design and implementation, information on the environmental attributes and CB scenarios, as well as information on the calculation of travel costs. In Sect. 3, we present the econometric approach before we move to the presentation of the results in Sect. 4. In Sect. 5, we discuss the results and conclude. 


\section{Data and Study Design}

\subsection{Survey Design and Implementation}

The data used in this study were collected by means of an online survey in Finland, Germany, and Latvia from November 2016 until February 2017. The survey was designed to reveal the diverse benefits that the Baltic Sea provides for human well-being with a particular focus on recreation but also included a choice experiment on reaching a good environmental status in the Baltic Sea. Pre-testing of the survey instrument included expert reviews by researchers in environmental valuation and marine ecology, focus groups, and a pilot survey in each country.

Stratified random sampling was used in all countries, stratifying on age, gender, and location, with the aim of obtaining a representative sample of the general population. For Germany, coastal regions were oversampled to increase the share of Baltic Sea visitors in the final sample. The data collection method in Finland and Germany was computerassisted web interviews (CAWI) with internet panels. The implementation method in Latvia combined computer-assisted personal interviews (CAPI) and CAWI (see Table 1). The CAPI were conducted at the respondent's place of residence. Altogether, 4800 respondents answered the survey, with a little over 2000 respondents in Finland and Germany and around 760 in Latvia. The average response time was around $20 \mathrm{~min}$.

The survey was organized in eight sections: (1) introduction to the survey, (2) questions on the respondents' recreation visits including mapping exercises, (3) questions on the last visit to the most often visited site, (4) introduction to the environmental attributes, (5) questions on the perceived quality of the most often visited site, (6) CB questions for hypothetical quality scenarios, (7) a choice experiment on reaching the good environmental status in the Baltic Sea and, finally, (8) debriefing questions and questions on the socioeconomic background of the respondents.

\subsection{Recreational Visits at the Baltic Sea and Perceived Environmental Quality}

The present study solely relies on those respondents who had visited the Baltic Sea recently, namely during the last three years prior to the survey. The share of recent Baltic Sea visitors varies substantially between the three countries, ranging from $61.1 \%$ of completed responses in Germany to $75.8 \%$ in Finland and $78.9 \%$ in Latvia. In the survey, the

Table 1 Survey implementation

\begin{tabular}{|c|c|c|c|}
\hline Country & Finland & Germany & Latvia \\
\hline Survey mode & CAWI & CAWI & CAWI and CAPI \\
\hline $\begin{array}{c}\text { Sample size (number of } \\
\text { completed responses) }\end{array}$ & 2048 & 2005 & 759 (CAWI: 351, CAPI: 408) \\
\hline Response rate (\%) & 34 & $15-20$ & 26.7 (CAWI: 18.5, CAPI: 43.3) \\
\hline $\begin{array}{l}\text { Age of sampled indi- } \\
\text { viduals (years) }\end{array}$ & $18-79$ & $18-77$ & $18-74$ \\
\hline Survey company & $\begin{array}{l}\text { Kantar TNS (formerly } \\
\text { TNS Gallup) }\end{array}$ & $\begin{array}{l}\text { Lightspeed Research } \\
\text { GmbH }\end{array}$ & Latvijas Fakti Ltd. \\
\hline
\end{tabular}




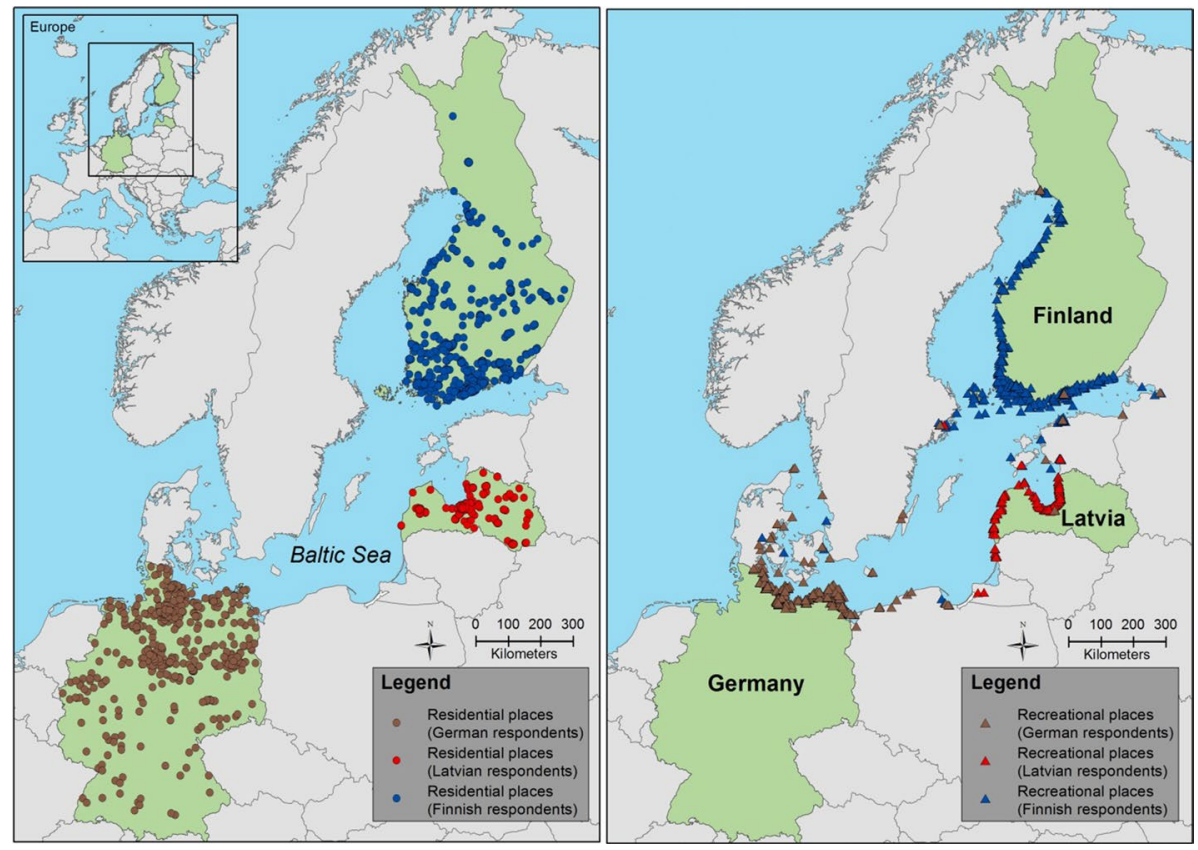

Fig. 1 Location of residential and recreational places per country

recent visitors were asked to locate their most often visited site on an interactive map that was integrated in the online survey. These sites could be located anywhere along the Baltic Sea coast, not necessarily in the respondent's home country. In addition, the respondents were asked about the activities they carried out at these sites, their travel time, distance, costs, and travel mode to get to the site, the duration of the last stay, and the motivation for their visit. Moreover, they were asked to locate their place of residence on the interactive map. Thus, travel distances to the most often visited site could be calculated using GIS (see Fig. 1).

Next, we introduced five attributes to describe recreational sites along the Baltic Sea coast and asked respondents to assess the perceived environmental quality at their most often visited site. The attributes were: (1) water clarity, (2) blue-green algal blooms, (3) algae onshore, (4) number of bird, plant, and fish species, and (5) facilities at the site. Table 10 in the "Appendix" shows the attributes and their levels together with the description presented to the respondents. Respondents were then asked how they would rate each of these attributes for their chosen Baltic Sea site. For example, for the water clarity attribute we asked: "Water clarity indicates how deep you can see under the surface. How would you describe water clarity at your most often visited site on average? turbid, rather turbid, rather clear, clear, don't know".

Moving from actual to hypothetical visits, the respondents were then asked how often they would visit their most often visited Baltic Sea site per year taking into account altered environmental conditions. In total, we presented three CB scenarios to each respondent and randomly assigned the quality levels (Table 10 in the "Appendix") to the five environmental attributes. Figure 2 provides the $\mathrm{CB}$ question and an example of a scenario which was presented to the respondents. The $\mathrm{CB}$ question explicitly stated that respondents should 


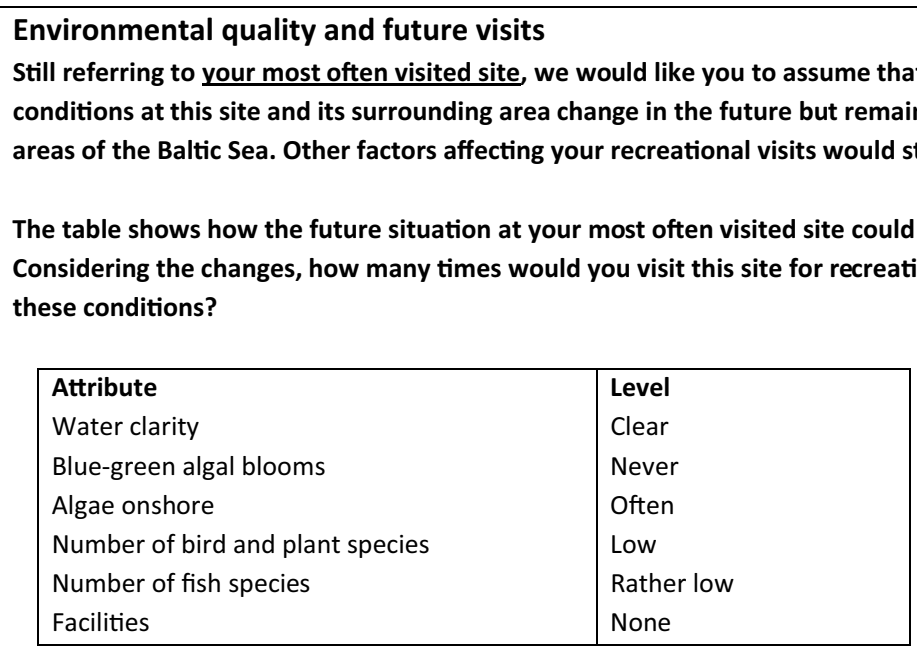

I would visit this site times per year.

Fig. 2 Contingent behavior question and example of a scenario with randomly assigned quality levels

assume that conditions would only change at their most often visited site and its surrounding area but not in the remaining parts of the Baltic Sea. We, therefore, ensure that conditions in the remaining Baltic Sea are kept constant and avoid having to make unrealistic assumptions when calculating the welfare estimates.

When describing the CB scenarios, we have used a qualitative scaling of the attribute levels instead of a quantitative one. This choice was driven by pre-testing of the valuation scenario and $\mathrm{CB}$ questions in focus group discussions and among experts in marine ecology. We explicitly tested quantitative levels for the attributes (e.g., water clarity in meters of sight depth and blue-green algal blooms in number of days per summer), but found focus group participants to object this presentation. Even though qualitative attribute levels might not be as explicit as quantitative descriptions, respondents may understand and interpret the changes differently even when quantitative attribute levels are used. For example, it has been shown for choice experiments that the range of the levels presented can influence welfare estimates and WTP (Luisetti et al. 2011). Moreover, using quantitative levels could lead to biased and unreliable welfare estimates if they are opposed by the respondents, as in our case. Given the findings from pre-testing, we opted for qualitative levels instead of taking the risk that quantitative levels would be misconceived and lead to biased estimates.

\subsection{Travel Costs}

For each respondent, we computed the Euclidean distance ${ }^{2}$ from the place of residence to the most often visited Baltic Sea site using ArcGIS as a basis for calculating travel costs.

\footnotetext{
2 Road distances were also calculated but using them would further reduce the number of observations due to missing values. Since the correlation between Euclidean and road distance is very high $(\rho=0.995)$, Euclidean distances were used for the final analysis.
} 
Stated travel distance was used when the respondents indicated that their journey did not start from home.

Travel costs included direct costs, such as costs for fuel, and indirect costs, such as opportunity costs of time. Direct travel costs were calculated based on motoring costs estimated by AA insurance company following Czajkowski et al. (2015). Motoring costs were adapted using national purchasing power parity (PPP) data from Eurostat (Eurostat 2017). Based on this, motoring costs were assumed to be $0.15 \mathrm{EUR} / \mathrm{km}$ for Finland, $0.13 \mathrm{EUR} / \mathrm{km}$ for Germany, and 0.08 EUR/km for Latvia. Direct travel costs were then calculated by multiplying the motoring costs per $\mathrm{km}$ with the roundtrip distance between the starting point of the journey and the most often visited Baltic Sea site for each respondent. Motoring costs were assumed to be zero if respondents walked to the site or went by bike, which was the case for $17.2 \%$ of the respondents in Finland, 2.1\% in Germany, and 6.9\% in Latvia. The vast majority of respondents drove by car to the most often visited recreational site at the Baltic Sea (51.1\% in Finland, $86.4 \%$ in Germany, and $71.7 \%$ in Latvia). ${ }^{3}$

Indirect travel costs, namely opportunity costs of time, were added to the direct travel costs for all respondents. Opportunity costs of time were conservatively calculated based on one-third of the respondent's individual net monthly income assuming 1700 working hours per year, which was the EU average of actual hours worked per year in 2016 (OECD 2018). Income was imputed for those respondents who had not reported it using univariate imputation with truncated regression as implemented in Stata 13. We used demographic characteristics of those respondents who reported income in an additional regression to fit income for the respondents who did not report it. The following variables were used: age, age squared, gender, education level, and employment status. Travel time was calculated based on the stated travel mode and assumed travel speed $(4 \mathrm{~km} / \mathrm{h}$ for walkers, $15 \mathrm{~km} / \mathrm{h}$ for bikers, and $70 \mathrm{~km} / \mathrm{h}$ for all others).

Finally, travel costs were weighted according to the purpose of the trip since a relatively large share of respondents stayed longer at the Baltic Sea, making it unlikely that recreation was the only purpose of the trip (Blayac et al. 2016; du Preez and Hosking 2011; MartínezEspiñeira and Amoako-Tuffour 2009). We weighted travel costs according to the respondents' responses to a rating scale. The rating scale and the assigned weights are given in Table 2. Descriptive statistics for weighted travel costs excluding and including opportunity costs of time are given in Table 3 .

\section{Econometric Approach}

Before implementing the CB model, a number of issues need to be addressed. First, our dependent variable, the number of visits to a specific site at the Baltic Sea coast per year, is a non-negative integer. Accordingly, a count data model was employed. Second, we employ a negative-binomial model to allow for overdispersion which is present in our data

\footnotetext{
${ }^{3}$ Depending on the country, 10-30\% of the respondents took some other mode of transport (e.g., public transport, private boat or ferry). We followed the approach taken in Czajkowski et al. (2015) and used motoring costs for all respondents who did not walk or bike. As the motoring costs are rather small, it is a conservative approach to use these as a proxy for travel costs.
} 
Table 2 Weighting of travel costs according to the purpose of the trip

\begin{tabular}{lc}
\hline Purpose: recreation at the sea was... & $\begin{array}{c}\text { Travel cost } \\
\text { weight (\%) }\end{array}$ \\
\hline ...the only purpose of the trip & 100 \\
...more important than other purposes, but it was not & 75 \\
the only purpose & 50 \\
...equally important as other purposes & 30 \\
...less important than other purposes & 10 \\
...only a small purpose of the trip & \\
\hline
\end{tabular}

as the mean of annual visits is substantially lower than the standard deviation (Table 3 ). Third, the dependent variable is a panel variable since we have more than one observation per respondent. The first observation per respondent refers to visits in the past under SQ conditions, while the other three observations refer to future visits under hypothetical conditions. Consequently, we estimated a panel data model with a random-effects specification to account for the fact that dispersion might vary across respondents for unidentified respondent-specific reasons (Cameron and Trivedi 2013; Englin and Cameron 1996). Similar negative binomial random-effects specifications have also been used by, e.g., Barry et al. (2011), Kragt et al. (2009), Christie et al. (2007), and Hanley et al. (2003). ${ }^{4}$

Note that CB models so far have mostly been applied to single sites with interviews being predominantly collected on-site (e.g., Barry et al. 2011; Rolfe and Dyack 2011; Christie et al. 2007; Bhat 2003). In contrast to this, our data was gathered using off-site sampling in three different countries neighboring the Baltic Sea, covering a range of sites such that we were not able to define a uniform SQ across the sites. Consequently, we asked respondents for their perceived environmental quality at the visited site, which gave us an individual SQ that varies across respondents. This technique has been used before in discrete choice experiments (e.g., Barton and Bergland 2010; Birol et al. 2009; Banzhaf et al. 2001) and site choice models (e.g., Adamowicz et al. 1997). In addition, since we use an individual SQ, we did not know in advance whether our CB scenarios implied improving or deteriorating environmental conditions for the respondents. Consequently, we separate between improvements and deteriorations in environmental quality in the econometric model to account for potentially asymmetric effects. This allows for differing preferences concerning decreases and increases in the quality indicated by the attributes levels relative to the SQ. ${ }^{5}$ A symmetric model, in contrast, would assume the same effects of changes in the gain and loss domain and thus potentially lose important information on the welfare effects.

\footnotetext{
${ }^{4}$ Note that the observed behavior, i.e., the reported number of visits to the Baltic Sea site, is truncated at zero because only visitors from the last three years are included in the sample. In the CB scenarios, respondents could choose not to visit the site anymore, e.g., if environmental conditions had deteriorated too much. Still, the number of visits reported for the CB scenarios can be considered incidentally truncated because of the correlation between observed behavior and contingent behavior for the same person. In principal, correction for truncation in panel data is possible (e.g., Hynes and Greene 2013; Egan and Herriges 2006). However, the average number of visits in our samples is between 5 and 13, which is rather far away from zero such that the bias from truncation can be considered relatively small. We thus do not correct for truncation and incidental truncation in this paper.

5 Using an individual perceived SQ avoids the problem of respondents' perceptions differing from the SQ specified in the survey, which may lead to unexplained variation and even bias in welfare estimates (Kataria et al. 2012; Marsh et al. 2011). However, it requires assuming that those who assess environmental conditions to be "good" are no different in unobservable characteristics than those who assess the exact same conditions at the exact same site as "bad". We thank the editor for pointing this out.
} 


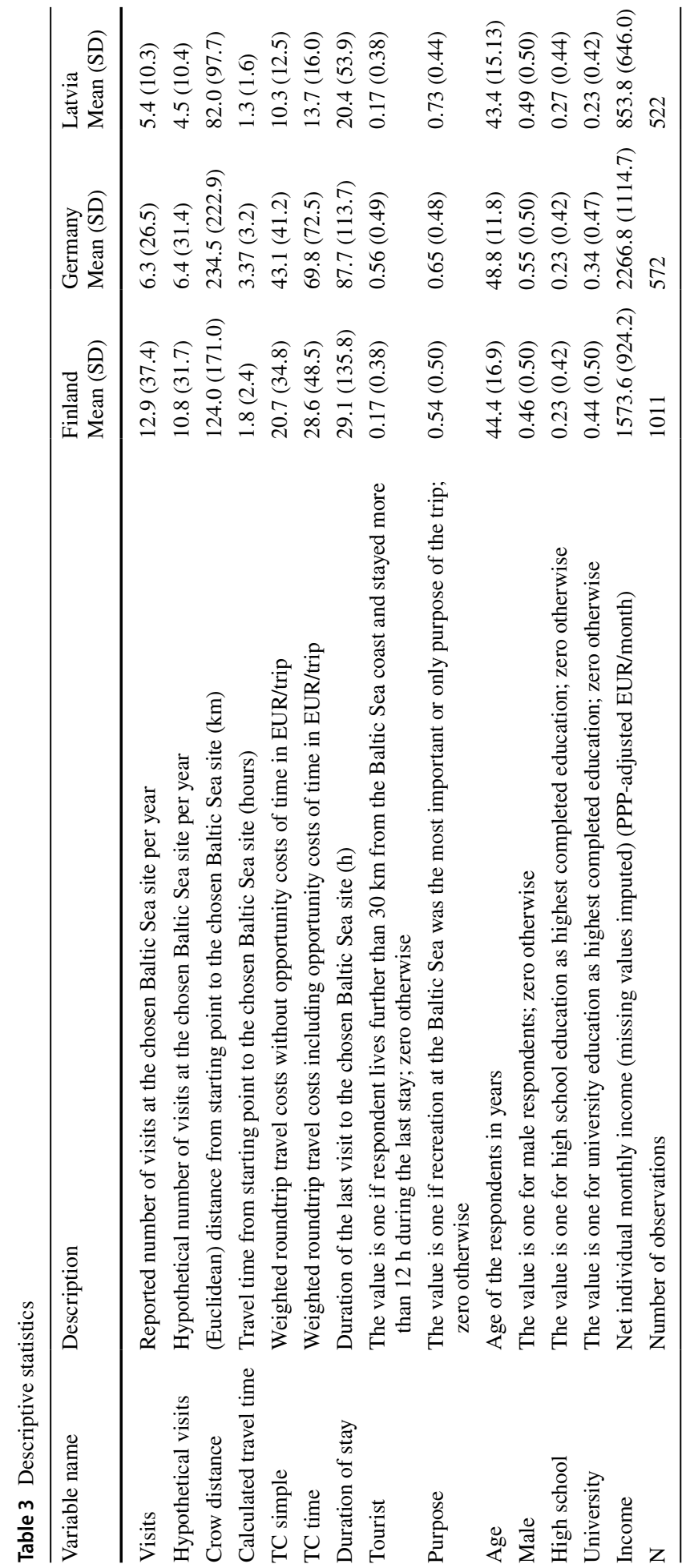


As a result of these considerations, we modelled the demand for trips to the Baltic Sea coast using two model specifications: a linear asymmetric model and a non-linear asymmetric model, which both allow for different welfare impacts resulting from improvements and deteriorations in environmental quality.

In the linear asymmetric model, the expected number of trips of respondent $i$ under quality conditions $q\left(\lambda_{i q}\right)$ was modeled as a function of individual travel costs $\left(t c_{i}\right)$, improvements of environmental site characteristics $\left(x_{l i q}^{+}\right)$, deteriorations of environmental site characteristics $\left(x_{l i q}^{-}\right)$, individual respondent characteristics $\left(x_{i}\right)$, and the model parameters $\boldsymbol{\beta}$ :

$$
\ln \left(\lambda_{i q}\right)=\beta_{t c_{i}} t c_{i}+\beta_{1}^{+} x_{1 i q}^{+}+\beta_{1}^{-} x_{1 i q}^{-}+\cdots+\beta_{5}^{+} x_{5 i q}^{+}+\beta_{5}^{-} x_{5 i q}^{-}+\boldsymbol{x}_{i}^{\prime} \boldsymbol{\beta}_{x_{i}} .
$$

The variables for environmental improvements and deteriorations were calculated as follows, based on the procedure applied by Hess et al. (2008), Masiero and Hensher (2010), Glenk (2011) and Ahtiainen et al. (2015):

$$
x_{i q}^{+}=\max \left(x_{i q}-x_{i 0}, 0\right), \quad \text { and } \quad x_{i q}^{-}=\max \left(x_{i 0}-x_{i q}, 0\right),
$$

where $x_{i q}$ is the environmental quality presented to respondent $i$ in one of the hypothetical CB scenarios, $q=1,2,3$, and $x_{i 0}$ is the environmental quality perceived by respondent $i$ in the SQ. Consequently, the variables $x_{i q}^{+}$and $x_{i q}^{-}$represent the differences in the attribute levels between the situation in the CB scenarios and the SQ levels for improvements and deteriorations, respectively. The variables were specified linearly, i.e., they have the value one if there was a one-level improvement or deterioration, the value two for a two-level change, and the value three for a three-level change. Otherwise, the variables have the value zero. Thus, the value of both variables is zero if there was no change between the SQ and the $\mathrm{CB}$ scenario. Moreover, both variables were also set to zero if the respondent did not give an indication of how she perceived the environmental quality in the SQ, thus if she chose the option "Don't know". From our point of view, this is reasonable since we assume that respondents who were not able to assess current environmental conditions would not react as sensitively to changes in environmental conditions as respondents who have experienced the current conditions.

In the non-linear asymmetric model, we defined two improvement levels $\left(x_{i q}^{+}, x_{i q}^{++}\right)$and two deterioration levels $\left(x_{i q}^{-}, x_{i q}^{--}\right)$, similarly to Masiero and Hensher (2010) and Ahtiainen et al. (2015). The variables $x_{i q}^{+}$and $x_{i q}^{-}$represent a one-step change relative to the SQ level. Two- and three-step improvements and deteriorations are pooled into the variables $x_{i q}^{++}$and $x_{i q}^{--}$, respectively, due to the small number of observations for three-step changes. The variables are dummy-coded. This specification allows us to examine possible non-linearities in the welfare effects. The non-linear asymmetric model is defined as follows:

$$
\begin{aligned}
\ln \left(\lambda_{i q}\right)= & \beta_{t c_{i}} t c_{i}+\beta_{1}^{+} x_{1 i q}^{+}+\beta_{1}^{++} x_{1 i q}^{++}+\beta_{1}^{-} x_{1 i q}^{-}+\beta_{1}^{--} x_{1 i q}^{--}+\cdots+\beta_{5}^{+} x_{5 i q}^{+}+\beta_{5}^{++} x_{5 i q}^{++} \\
& +\beta_{5}^{-} x_{5 i q}^{-}+\beta_{5}^{--} x_{5 i q}^{--}+\boldsymbol{x}_{i}^{\prime} \boldsymbol{\beta}_{x_{i}}
\end{aligned}
$$

Finally, we applied a random-effects negative binomial model with beta-distributed individual random effects to estimate the model coefficients. Consequently, we assumed that the number of trips is identically and independently distributed according to a mean dispersion negative binomial distribution (NB2) with parameters $\alpha_{i} \lambda_{i q}$ and $\phi_{i}$, where $\lambda_{i q}=\exp \left(\boldsymbol{x}_{i q}{ }^{\prime} \boldsymbol{\beta}\right)$, such that the number of trips has mean $\alpha_{i} \lambda_{i q} / \phi_{i}$ and variance $\left(\alpha_{i} \lambda_{i q} / \phi_{i}\right) *\left(1+\alpha_{i} / \phi_{i}\right)$. It is assumed that $\left(1+\alpha_{i} / \phi_{i}\right)^{-1}$ is a beta-distributed random variable with parameters $(r, s)$. This implies that we do not have one fixed overdispersion parameter for the whole sample 
but that overdispersion can randomly vary following a beta distribution. It thus captures, to some extent, potential heterogeneity among the respondents (Cameron and Trivedi 2013).

Given the log-linear form of the demand function (1), consumer surplus (CS) per trip can be calculated as

$$
C S_{i, t r i p}=\frac{-1}{\beta_{t c_{i}}}
$$

The effect of varying environmental quality on CS can be calculated in different ways. First, it is possible to define interaction variables between the quality attributes and travel costs. A significant interaction term would imply that the number of visits reacts differently to changes in travel costs when different quality levels are observed. This would directly imply different CS estimates per trip given different quality levels (Lankia et al. 2019). If these interaction terms were not significant, CS per trip would not vary depending on the environmental quality observed.

Second, it is also possible that changes in environmental quality induce changes in the expected number of trips during a certain period. Consequently, CS per visitor per time period (e.g., 1 year), would change with changing environmental quality while CS per trip would stay constant. The corresponding change in CS per time period induced by changes in environmental quality can then be calculated by dividing the change in the predicted number of trips by the coefficient of the travel cost variable. Note that the relevant comparison in welfare terms is between predicted trips at the current water quality level and predicted trips at the changed level (Hanley et al. 2003; Bockstael et al. 1984). Thus

$$
\Delta C S_{i, y e a r}=\frac{-1}{\beta_{t c_{i}}}\left(\lambda_{i}\left(t c_{i}, \boldsymbol{x}_{i}, q_{1}\right)-\lambda_{i}\left(t c_{i}, \boldsymbol{x}_{i}, q_{0}\right)\right) .
$$

\section{Results}

\subsection{Descriptive statistics and results}

The reported number of visits per year varies substantially among the three countries (Table 3). It is largest in Finland, where the mean number of visits is 12.9, while it only amounts to 6.3 in Germany and 5.4 in Latvia. Respondents from Finland are thus more frequent visitors of their most often visited Baltic Sea site compared to respondents from Germany and Latvia. Moving from reported to hypothetical visits, it is noticeable that the average number of visits declines for the changed environmental conditions for Finland and Latvia while it stays nearly the same for Germany.

The mean Euclidean distance between residence and most often visited recreation site, mean travel time, and mean travel costs per country are interrelated and influenced by the size and shape of the three countries. Respondents from Germany travel furthest and longest to their favorite Baltic Sea sites, with distances being almost three time larger compared to Latvia. Respondents from Finland face intermediate levels of distance and travel time to travel to their most often visited Baltic Sea site. This carries over to varying levels of travel costs. These findings reflect the sizes of the different countries, as Latvia is much smaller than Germany and Finland. But it also reflects the fact that Finns live on average closer to the Baltic Sea than Germans even though the countries have a similar size. Moreover, these 


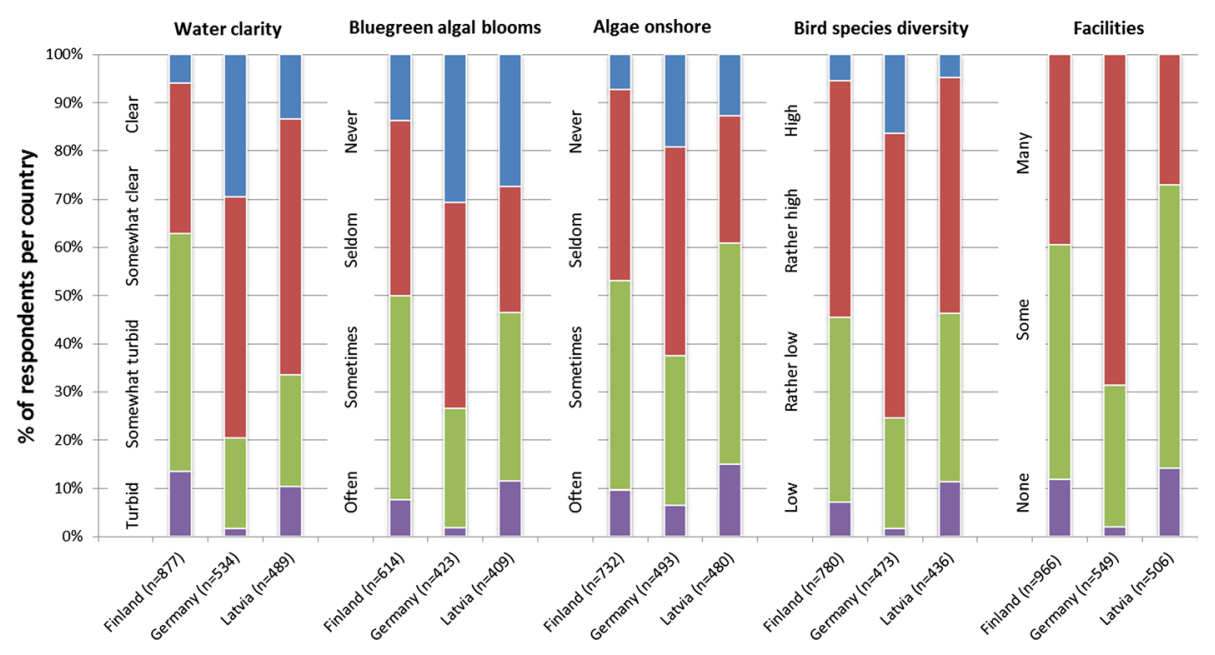

Fig. 3 Perceptions of quality attributes in the three countries

findings also reflect the fact that the German sample contains a much larger share of tourists, i.e., respondents who live more than $30 \mathrm{~km}$ away from the Baltic Sea and stayed more than $12 \mathrm{~h}$ at the site (56\% tourists in Germany compared to $17 \%$ in Finland and Latvia). Related to this, looking at the map in Fig. 1, it seems that respondents from Germany more often chose a Baltic Sea site outside of their own country than respondents from the other countries, which also explains larger distances, travel times, and travel costs.

Regarding other socio-economic characteristics, respondents from Germany are on average four to 5 years older than respondents from Finland and Latvia. The share of respondents with high school education as their highest educational level is similar between countries. The share of university educated respondents, however, varies substantially between countries (44\% in Finland, 34\% in Germany, and 23\% in Latvia). Income adjusted for PPP is highest in the German sample and lowest in the Latvian sample.

The respondents' perceptions of the average environmental conditions at their most often visited Baltic Sea site differ among the countries and quality attributes (Fig. 3). Overall, environmental quality is seemingly perceived to be better in Germany than in Finland and Latvia. For the water clarity attribute, for example, almost $80 \%$ of the respondents from Germany perceive the water to be clear or somewhat clear, while this share only amounts to $66 \%$ in Latvia and $38 \%$ in Finland. Similar patterns hold for the other environmental attributes (blue-green algal blooms, algae onshore, and bird species diversity) and for the attribute facilities at the site. Almost $70 \%$ of the respondents from Germany describe their Baltic Sea sites as being equipped with many facilities. This only holds for $39 \%$ of the favorite sites in Finland and $27 \%$ of the favorite sites in Latvia.

Our findings correspond to previous studies, where German respondents have been found to be the least concerned of the environmental status of the Baltic Sea (Ahtiainen et al. 2013, 2014), and have the most positive perceptions of the local environmental status (i.e., the German marine waters of the Baltic Sea) of all the coastal countries (Ahtiainen et al. 2013; Czajkowski et al. 2015). There are no evident differences in actual environmental quality in the sub-basins adjacent to Germany compared to those adjacent to Finland and Latvia, at least on the sub-basin level (HELCOM 2018). Thus, the differences in 
perceptions are likely rooted in other factors we can only hypothesize about. One reason could be that the water quality at substitute sites is much lower in Germany than in Finland. Another reason could be that German respondents, who live on average much further away from the Baltic Sea than Finnish respondents, have a lower attachment to the Baltic Sea and are thus less concerned about its environmental state. However, as the spatial aggregation of the HELCOM data is quite coarse, it is also possible that there are more pronounced differences in environmental quality closer to the shore where they are experienced by the respondents.

The respondents used all categories when rating the perceived environmental quality at their most often visited sites, but the more "extreme" categories were chosen less often than the middle categories. For example, respondents from Germany chose the best category in $30 \%$ of the cases for the attributes water clarity and blue-green algal blooms, and in $20 \%$ of the cases for algae onshore. Also, respondents from Latvia chose the best category for the attribute blue-green algal blooms in almost $30 \%$ of the cases and in more than $10 \%$ of the cases for the attributes water clarity and algae onshore. The worst categories were chosen less often in all countries.

Table 4 shows the share of respondents who faced an improvement or a deterioration in the hypothetical CB scenarios compared to their perceived SQ situation. The reported share is the average share for the three hypothetical situations separated by country. The share of respondents who did neither face an improvement nor a deterioration did either not face a change in the CB scenarios or did not indicate their perceptions of the respective quality attribute for the SQ. This is valuable information to get an overview for which attributes and in which countries respondents were more faced with improving or deteriorating situations.

The quality levels presented to the respondents in the hypothetical situations were randomized. Consequently, the probability to face a quality improvement in a $\mathrm{CB}$ scenario would increase when the respondent observed low quality levels for the actually visited site (SQ). Likewise, the probability to face quality deteriorations in a hypothetical CB scenario would increase when high quality levels were reported for the SQ at the actually visited site. This is reflected in Table 4. For the attribute water clarity, for example, respondents from Germany faced quality deteriorations in $48 \%$ of all situations averaged over all CB scenarios, but improvements in only $23 \%$ of all situations. In Finland and Latvia, this relation was more balanced. The same pattern can be observed for the other attributes. This reflects the finding that respondents from Germany, overall, perceived environmental conditions in the SQ to be better than respondents from the other countries.

Since respondents in the three countries differ strongly in their perceptions of the SQ, also the reference point differs (see Table 5). For example, median perceptions of water clarity are lower for Finland than for Germany and Latvia. For blue-green algal blooms and bird species diversity, the median perception is equal across all three countries. For the attributes algae onshore and facilities, in contrast, median perceptions are better for Germany than for Finland and Latvia. Taking also mean perceptions into account, environmental quality is seemingly perceived to be better in Germany than in Finland and Latvia (compare also Fig. 3). It can thus be expected that the estimation results will differ among countries regarding whether improvements or deteriorations are considered. In particular, the perceived environmental quality at the most often visited site is likely to influence the respondents' preferences for environmental conditions, and thus the impact of environmental changes on individual recreational behavior. Thus, it is important to allow for differing reference points across the countries, and to discuss the results relative to the reference condition. 
Table 4 Average share of improvements and deteriorations in contingent behavior scenarios compared to the perceived SQ

\begin{tabular}{lccc}
\hline & Finland & Germany & Latvia \\
\hline Water clarity & & & \\
Improvements & $37.0 \%$ & $22.9 \%$ & $30.7 \%$ \\
Deteriorations & $27.5 \%$ & $47.7 \%$ & $39.8 \%$ \\
Blue-green algal blooms & & & \\
Improvements & $22.1 \%$ & $18.5 \%$ & $23.9 \%$ \\
Deteriorations & $24.0 \%$ & $37.1 \%$ & $33.2 \%$ \\
Algae onshore & & & \\
Improvements & $28.9 \%$ & $26.9 \%$ & $37.4 \%$ \\
Deteriorations & $26.1 \%$ & $38.0 \%$ & $31.0 \%$ \\
Bird species diversity & & & \\
Improvements & $28.8 \%$ & $23.5 \%$ & $33.3 \%$ \\
Deteriorations & $29.4 \%$ & $39.6 \%$ & $29.9 \%$ \\
Facilities & & & \\
Improvements & $22.4 \%$ & $11.6 \%$ & $28.1 \%$ \\
Deteriorations & $41.4 \%$ & $51.3 \%$ & $38.8 \%$ \\
$\mathrm{~N}$ & 1011 & 572 & 522 \\
\hline
\end{tabular}

Table 5 Attribute levels in the best and worst case scenarios and average SQ perceptions per country

\begin{tabular}{llllll}
\hline & Best level & Worst level & $\begin{array}{l}\text { Average percep- } \\
\text { tion (Finland) } \\
\text { (median/mean) }\end{array}$ & $\begin{array}{l}\text { Average percep- } \\
\text { tion (Germany) } \\
\text { (median/mean) }\end{array}$ & $\begin{array}{l}\text { Average } \\
\text { perception } \\
\text { (Latvia) } \\
\text { (median/ } \\
\text { mean) }\end{array}$ \\
\hline Water clarity & & & & $2 / 1.70$ \\
Blue green algal blooms & 0 (never) & 3 (often) & $1 / 1.44$ & $1 / 0.98$ & $1 / 1.31$ \\
Algae onshore & 0 (never) & 3 (often) & $2 / 1.55$ & $1 / 1.25$ & $2 / 1.63$ \\
Bird and plant diversity & 3 (high) & 0 (low) & $2 / 1.53$ & $2 / 1.90$ & $2 / 1.47$ \\
Facilities & 2 (many) & 0 (none) & $1 / 1.28$ & $2 / 1.67$ & $1 / 1.13$ \\
\hline
\end{tabular}

For blue green algal blooms and algae onshore, higher values indicate worse conditions

\subsection{Estimation Results}

In Table 6, we present the estimation results for the linear asymmetric negative binomial random-effects model estimated separately for each country. The test statistics of a likelihood ratio test comparing a model with a beta-distributed overdispersion parameter to a constant dispersion model indicate that the random-effects panel model fits the data better than the pooled model for all countries.

In the linear asymmetric model, travel costs (TC time) have a negative and significant influence on the number of visits in all countries, as expected. Even though quality changes are not always significant, the estimated coefficients have the expected signs for the attributes water clarity, blue-green algal blooms, algae onshore, and bird species diversity. For all the environmental attributes, improvements have a positive and deteriorations a negative 
Table 6 Estimation results for the linear asymmetric negative binomial random-effects model

\begin{tabular}{|c|c|c|c|}
\hline $\begin{array}{l}\text { Dependent variable: } \\
\text { annual number of visits }\end{array}$ & $\begin{array}{l}\text { Finland } \\
\text { coefficient (SE) }\end{array}$ & $\begin{array}{l}\text { Germany } \\
\text { coefficient (SE) }\end{array}$ & $\begin{array}{l}\text { Latvia } \\
\text { coefficient (SE) }\end{array}$ \\
\hline TC time & $-0.0027 * * *(0.0007)$ & $-0.0024 * * *(0.0006)$ & $-0.0155^{* * *}(0.0031)$ \\
\hline Water clarity + & $0.1370 * * *(0.0181)$ & $0.0465(0.0435)$ & $0.0904 * * *(0.0310)$ \\
\hline Water clarity - & $\begin{array}{l}-0.0679^{* * *}(0.0241) \\
71.87^{\mathrm{a}}\end{array}$ & $\begin{array}{l}-0.1919 * * *(0.0279) \\
31.27^{\mathrm{a}}\end{array}$ & $\begin{array}{l}-0.2674 * * *(0.0314) \\
103.98^{\mathrm{a}}\end{array}$ \\
\hline Blue-green algae + & $0.1059 * * *(0.0218)$ & $0.0828 *(0.0459)$ & $0.0405(0.0301)$ \\
\hline Blue-green algae - & $\begin{array}{l}-0.1334 * * *(0.0227) \\
84.7^{\mathrm{a}}\end{array}$ & $\begin{array}{l}-0.0315(0.0301) \\
6.15^{\mathrm{a}}\end{array}$ & $\begin{array}{l}-0.1234 * * *(0.0289) \\
20.89^{\mathrm{a}}\end{array}$ \\
\hline Algae onshore + & $0.0001(0.0204)$ & $0.1136 * * *(0.0353)$ & $0.0340(0.0259)$ \\
\hline Algae onshore - & $\begin{array}{l}-0.0707 * * *(0.0228) \\
8.07^{\mathrm{a}}\end{array}$ & $\begin{array}{l}-0.0528^{*}(0.0315) \\
19.14^{\mathrm{a}}\end{array}$ & $\begin{array}{l}-0.0475(0.0343) \\
5.33^{\mathrm{a}}\end{array}$ \\
\hline Bird diversity + & $0.0462 * *(0.0221)$ & $0.0726^{*}(0.0434)$ & $-0.0196(0.0317)$ \\
\hline Bird diversity - & $\begin{array}{l}-0.0247(0.0221) \\
8.29^{\mathrm{a}}\end{array}$ & $\begin{array}{l}-0.0686^{* *}(0.0300) \\
10.94^{\mathrm{a}}\end{array}$ & $\begin{array}{l}0.0176(0.0346) \\
0.99^{\mathrm{a}}\end{array}$ \\
\hline Facilities+ & $-0.0918 * * *(0.0282)$ & $0.1070(0.0695)$ & $0.0194(0.0434)$ \\
\hline Facilities- & $\begin{array}{l}-0.1746^{* * *}(0.0233) \\
7.27^{\mathrm{a}}\end{array}$ & $\begin{array}{l}-0.1064 * * *(0.0312) \\
9.60^{\mathrm{a}}\end{array}$ & $\begin{array}{l}-0.0796^{* *}(0.0371) \\
4.65^{\mathrm{a}}\end{array}$ \\
\hline Hypothetical & $-0.0950 * *(0.0402)$ & $0.0623(0.0671)$ & $-0.0701(0.0631)$ \\
\hline Purpose & $0.2185 * * *(0.0608)$ & $0.2851 * * *(0.0794)$ & $0.2000 * *(0.0855)$ \\
\hline Tourist & $-0.2071 * *(0.0888)$ & $-0.1343 *(0.0788)$ & $-0.1698(0.1296)$ \\
\hline Age & $0.0096 * * *(0.0020)$ & $0.0021(0.0033)$ & $-0.0016(0.0024)$ \\
\hline Male & $-0.2152 * * *(0.0654)$ & $0.0328(0.0759)$ & $0.0329(0.0758)$ \\
\hline High school & $-0.1384 *(0.0817)$ & $-0.2318 * *(0.0951)$ & $-0.0944(0.0887)$ \\
\hline University & $0.0039(0.0722)$ & $-0.0441(0.0861)$ & $0.3687 * * *(0.0989)$ \\
\hline Income & $0.0001 * * *(0.0000)$ & $-0.0000(0.0000)$ & $0.0001(0.0001)$ \\
\hline Constant & $1.1389 * * *(0.1140)$ & $1.2983^{* * *}(0.2127)$ & $1.7400(0.1718)$ \\
\hline $\operatorname{Ln}(r)^{b}$ & $0.6438(0.0479)$ & $0.9734(0.0680)$ & $1.3931(0.0773)$ \\
\hline $\operatorname{Ln}(s)^{b}$ & $0.5053(0.0533)$ & $0.6921(0.0758)$ & $0.9155(0.0802)$ \\
\hline Log likelihood & $-10,522.9$ & -4902.2 & -4586.7 \\
\hline AIC & $21,089.9$ & 9848.3 & 9217.5 \\
\hline BIC & $21,228.5$ & 9974.5 & 9341.6 \\
\hline $\mathrm{N}$ & 1011 & 572 & 522 \\
\hline
\end{tabular}

$* p<0.1, * * p<0.05, * * * p<0.01$. LR test RE versus pooled model: $\bar{\chi}^{2}=4985.41(p=0.000)$ for Finland, $\bar{\chi}^{2}=2486.04(p=0.000)$ for Germany, and $\bar{\chi}^{2}=1512.69(p=0.000)$ for Latvia

${ }^{a}$ Wald test: $\chi^{2}(1)$ statistic for the difference between decrease and increase parameters using absolute values $\left(\mathrm{H} 0: \beta^{+}=\beta^{-}\right)$. Value $>3.841$ indicates a significant difference at the $5 \%$ level

${ }^{\mathrm{b}} \ln (\mathrm{r})$ and $\ln (\mathrm{s})$ are the estimated parameters of the beta distribution describing the variation of the overdispersion parameter (see Sect. 3)

effect. Overall, there seem to be asymmetries in the effects on the number of trips relative to the reference point, as the coefficients for improvements and deteriorations differ in their absolute value and sometimes significance. This is confirmed by Wald tests to determine whether the differences in the absolute values of the parameters for improvements and 
deteriorations are significantly different from zero. The tests indicate significant differences at the 5\% level for all cases, except for the bird diversity attribute for Latvia.

Note that the estimated coefficients are half-elasticities, implying that they represent a percentage change in the number of visits induced by a one unit change in the respective explanatory variable. Taking the attribute water clarity as an example, this implies that a one level increase in water clarity would ceteris paribus increase the expected number of visits by $9 \%$ for the case of Latvian respondents. A one level decrease in water clarity, in contrast, would ceteris paribus decrease the expected number of visits by $27 \%$ for Latvian respondents.

The results do not paint a clear picture of whether deteriorations or improvements result in larger relative effects on the number of trips, as these differ by attribute and country. For the attribute water clarity, for example, both improvements and deteriorations have a significant effect on the number of visits for the case of Finland and Latvia, while for Germany only deteriorations have a significant effect. For Finland, improvements in water clarity have a stronger relative impact on the number of visits than deteriorations. The opposite result can be observed for Latvia, where deteriorations in water clarity have a stronger relative impact on the number of visits than improvements. The reason for this pattern might be that respondents in Germany and Latvia perceive water clarity as being rather clear. As described above, $80 \%$ of the German respondents and a little less than $70 \%$ of the Latvian respondents perceive the water at their most often visited Baltic Sea site to be clear or rather clear. This share only amounts to $35 \%$ in Finland. Consequently, respondents from Finland would greatly appreciate improvements in water clarity but would also react to further deteriorations. Respondents from Germany and Latvia, in contrast, would not benefit from further improvements but would strongly react to deteriorations, which would constitute a greater "loss" for them.

The effect of the attribute facilities merits closer attention. For Germany and Latvia, an increase in the number of facilities does not have a significant effect but the effect of a decrease in the number of facilities is significantly negative. Respondents from Germany and Latvia would thus be significantly negatively affected by decreasing facility levels at their most often visited sites. For Finland, however, both increasing and decreasing the number of facilities would have a significantly negative impact on the number of visits. Consequently, respondents from Finland seem to prefer the current equipment of the recreation sites they have selected, and would visit less often given changes in any direction.

The results of the non-linear asymmetric model are, in many respects, similar to the linear model (Table 7). The coefficient for travel costs is again negatively significant and of the same magnitude as in the linear model. In general, improvements have a positive and deteriorations a negative impact on the number of visits, but there are notable differences across countries. Regarding the environmental attributes, changes in water clarity are significant in explaining the number of visits in all countries, with deteriorations leading to larger relative impacts in Germany and Latvia and improvements leading to larger relative impacts in Finland. Regarding the other environmental quality attributes, blue-green algae and algae onshore explain the number of visits at least to some extent. The bird diversity attribute is insignificant in Germany and Latvia and only weakly significant in Finland. Changes in the number of facilities in any direction lead to reductions in visits for Finland, while for the case of Germany only decreases in facilities have a negative effect on the number of visits.

We used Wald tests to assess whether there were non-linearities in the relative effects of single attributes on the number of visits for single attributes, separately for improvements and deteriorations. The results indicated significant non-linear effects only for 
Table 7 Estimation results for the non-linear asymmetric negative binomial random-effects model

\begin{tabular}{|c|c|c|c|}
\hline $\begin{array}{l}\text { Dependent variable: annual } \\
\text { number of visits }\end{array}$ & $\begin{array}{l}\text { Finland } \\
\text { coefficient (SE) }\end{array}$ & $\begin{array}{l}\text { Germany } \\
\text { coefficient (SE) }\end{array}$ & $\begin{array}{l}\text { Latvia } \\
\text { coefficient (SE) }\end{array}$ \\
\hline TC time & $-0.0028 * * *(0.0007)$ & $-0.0024 * * *(0.0006)$ & $-0.0158 * * *(0.0031)$ \\
\hline Water clarity + & $0.1961 * * *(0.0387)$ & $0.0320(0.0712)$ & $0.1207 * *(0.5731)$ \\
\hline \multirow[t]{2}{*}{ Water clarity ++ } & $0.3083 * * *(0.0421)$ & $0.1576(0.1020)$ & $0.1820 * *(0.0754)$ \\
\hline & $1.47^{\mathrm{a}}$ & $0.39^{\mathrm{a}}$ & $0.28^{\mathrm{a}}$ \\
\hline Water clarity - & $-0.0595(0.0429)$ & $-0.1352 * *(0.0624)$ & $-0.2857 * * *(0.0633)$ \\
\hline \multirow[t]{2}{*}{ Water clarity -- } & $-0.1219 * *(0.0557)$ & $-0.4320 * * *(0.0656)$ & $-0.5549 * * *(0.0710)$ \\
\hline & $0.00^{\mathrm{a}}$ & $2.03^{\mathrm{a}}$ & $0.02^{\mathrm{a}}$ \\
\hline Blue-green algae + & $0.1033 * *(0.0426)$ & $0.1338 *(0.0712)$ & $-0.0057(0.0678)$ \\
\hline \multirow[t]{2}{*}{ Blue-green algae ++ } & $0.2505 * * *(0.0491)$ & $0.1237(0.1088)$ & $0.1059(0.0713)$ \\
\hline & $0.28^{\mathrm{a}}$ & $0.90^{\mathrm{a}}$ & $0.76^{\mathrm{a}}$ \\
\hline Blue-green algae - & $-0.0676(0.0420)$ & $-0.0133(0.0654)$ & $-0.0283(0.0622)$ \\
\hline \multirow[t]{2}{*}{ Blue-green algae -- } & $-0.3341 * * *(0.0550)$ & $-0.0824(0.0712)$ & $-0.3156^{* * *}(0.0734)$ \\
\hline & $5.38^{\mathrm{a}}$ & $0.21^{\mathrm{a}}$ & $4.41^{\mathrm{a}}$ \\
\hline Algae onshore + & $0.0200(0.0405)$ & $0.1224 *(0.0686)$ & $0.0908(0.0610)$ \\
\hline \multirow[t]{2}{*}{ Algae onshore ++} & $0.0207(0.0465)$ & $0.2253 * * *(0.0811)$ & $0.0914(0.0616)$ \\
\hline & $0.06^{\mathrm{a}}$ & $0.02^{\mathrm{a}}$ & $0.67^{\mathrm{a}}$ \\
\hline Algae onshore - & $-0.0592(0.0421)$ & $-0.0643(0.0683)$ & $-0.0395(0.0639)$ \\
\hline \multirow[t]{2}{*}{ Algae onshore -- } & $-0.1309 * *(0.0523)$ & $-0.0976(0.0734)$ & $-.00895(0.0832)$ \\
\hline & $0.02^{\mathrm{a}}$ & $0.06^{\mathrm{a}}$ & $0.01^{\mathrm{a}}$ \\
\hline Bird diversity + & $0.0786^{*}(0.0400)$ & $0.1609(0.0669)$ & $-0.0589(0.0616)$ \\
\hline \multirow[t]{2}{*}{ Bird diversity ++} & $0.0891 *(0.0512)$ & $0.0476(0.1060)$ & $-0.0106(0.0740)$ \\
\hline & $0.75^{\mathrm{a}}$ & $3.48^{\mathrm{a}}$ & $0.79^{\mathrm{a}}$ \\
\hline Bird diversity - & $-0.0088(0.0398)$ & $-0.0695(0.0669)$ & $-0.0298(0.0614)$ \\
\hline \multirow[t]{2}{*}{ Bird diversity -- } & $-0.0387(0.0491)$ & $-0.1054(0.0702)$ & $0.0210(0.0772)$ \\
\hline & $0.08^{\mathrm{a}}$ & $0.07^{\mathrm{a}}$ & $0.47^{\mathrm{a}}$ \\
\hline Facilities + & $0.0031(0.0377)$ & $0.1115(0.0789)$ & $0.0922(0.0564)$ \\
\hline \multirow[t]{2}{*}{ Facilities ++ } & $-0.3569 * * *(0.0763)$ & $0.1752(0.2427)$ & $-0.1101(0.0119)$ \\
\hline & $14.69^{\mathrm{a}}$ & $0.03^{\mathrm{a}}$ & $4.13^{\mathrm{a}}$ \\
\hline Facilities- & $-0.1492 * * *(0.0351)$ & $-0.1095 *(0.0559)$ & $-0.0723(0.0551)$ \\
\hline \multirow[t]{2}{*}{ Facilities-- } & $-0.3263 * * *(0.0519)$ & $-0.2147 * * *(0.0645)$ & $-0.1039(0.0832)$ \\
\hline & $0.38^{\mathrm{a}}$ & $2.33^{\mathrm{a}}$ & $0.05^{\mathrm{a}}$ \\
\hline Hypothetical & $-0.1652 * * *(0.0456)$ & $0.0221(0.0772)$ & $-0.1051(0.0759)$ \\
\hline Purpose & $0.2248 * * *(0.0607)$ & $0.2863 * * *(0.0797)$ & $0.2040 * *(0.0854)$ \\
\hline Tourist & $-0.2113^{* *}(0.0885)$ & $-0.1358 *(0.0794)$ & $-0.1645(0.1300)$ \\
\hline Age & $0.0094 * * *(0.0020)$ & $0.0018(0.0033)$ & $-0.0013(0.1300)$ \\
\hline Male & $-0.2051 * * *(0.0654)$ & $0.0344(0.0760)$ & $0.0376(0.0024)$ \\
\hline High school & $-0.1524 *(0.0817)$ & $-0.0238 * *(0.0955)$ & $-0.1012(0.0760)$ \\
\hline University & $-0.0055(0.0724)$ & $-0.0456(0.0864)$ & $0.3636 * * *(0.0890)$ \\
\hline Income & $0.0001 * * *(0.0000)$ & $-0.0000(0.0000)$ & $0.0001(0.0990)$ \\
\hline Constant & $1.1652 * * *(0.1141)$ & $1.3126^{* * *}(0.2134)$ & $1.7440 * * *(0.1720)$ \\
\hline $\operatorname{Ln}(r)^{b}$ & $0.6539(0.0479)$ & $0.9731(0.0681)$ & $1.4036(0.0775)$ \\
\hline $\operatorname{Ln}(s)^{b}$ & $0.5096(0.0534)$ & $0.6895(0.0760)$ & $0.9114(0.0801)$ \\
\hline Log likelihood & $-10,510.3$ & -4900.5 & -4579.6 \\
\hline AIC & $21,084.5$ & 9864.9 & 9223.2 \\
\hline BIC & $21,286.3$ & $10,048.5$ & 9403.8 \\
\hline $\mathrm{N}$ & 1011 & 572 & 522 \\
\hline
\end{tabular}

${ }^{*} p<0.1,{ }^{*} p<0.05,{ }^{* * *} p<0.01$. LR test RE versus pooled model: $\bar{\chi}^{2}=4988.72(p=0.000)$ for Finland, $\bar{\chi}^{2}=2481.43$ $(p=0.000)$ for Germany, and $\bar{\chi}^{2}=1519.81(p=0.000)$ for Latvia

${ }^{a}$ Wald test: $\chi^{2}(1)$ statistic for the difference between the coefficients for the small and large change $\left(\mathrm{H} 0: 2 \beta^{+}=\beta^{++}\right.$, $2 \beta^{-}=\beta^{-}$). Value $>3.841$ indicates a significant difference at the $5 \%$ level

${ }^{\mathrm{b}} \ln (\mathrm{r})$ and $\ln (\mathrm{s})$ are the estimated parameters of the beta distribution describing the variation of the overdispersion parameter (see Sect. 3) 
deteriorations in blue-green algal blooms and increases in facilities both for Finland and Latvia. No significant non-linear effects were found for Germany. ${ }^{6}$ In addition, we performed a likelihood ratio (LR) test to test whether the linear or the non-linear asymmetric model would fit the data better. For Germany and Latvia, no significant difference could be detected ( $p=0.9705$ and $p=0.1596$, respectively), such that a linear asymmetric model should suffice to fit the data. This is supported by the lower values of AIC and BIC for the linear specification. For Finland, in contrast, the likelihood ratio test indicated that the nonlinear model fits the data significantly better $(p=0.0048)$, also reflected by the lower AIC and $\mathrm{BIC}$ values.

\subsection{Scenario Analysis for Changes in Annual Consumer Surplus}

In this section, we present estimated changes in the expected number of visits and individual CS per year for selected scenarios (Table 8). We first predicted the expected number of visits under the assumption that all environmental quality attributes (water clarity, blue-green algae, algae onshore and bird diversity) obtain their best and worst levels and facilities are at their SQ level (Scenario I and II). Second, we assumed that environmental quality attributes would be at their SQ levels, but the number of facilities would change to the highest (many) or lowest (none) level (Scenario III and IV). In all cases, we consider changes in relation to the respondents' perceived SQ (see also Table 5). Additional scenarios, as well as welfare estimates for individual attributes are provided in Table S6 in the supplementary online material.

When interpreting the results, it is important to keep in mind that there are differences in the SQ levels of the attributes across countries. Respondents from Germany perceive the environmental conditions at their most often visited site to be better than the respondents from Finland and Latvia (Table 5). Thus the average improvement for German respondents (averaged over all four environmental attributes, excluding facilities) is approximately one level (1.1) when moving from the perceived SQ to the best environmental scenario. The average improvement for Finnish and Latvian respondents, in contrast, is 1.5 and 1.4 levels, respectively. Likewise, the deterioration is on average larger for respondents from Germany (1.9 levels) when moving from the perceived SQ to the worst environmental scenario, compared to 1.5 levels for Finland and 1.6 levels for Latvia. Thus, changes from the SQ level to the best and the worst environmental scenarios are similar-sized for Finland and Latvia (approximately 1.5 levels), while for Germany the change from the SQ to the worst environmental scenario is larger (1.9) than the change to the best environmental scenario (1.1). For facilities, the changes from the SQ to the highest level (many facilities) are 0.7, 0.3 and 0.9 and to the lowest level (no facilities) are 1.3, 1.7 and 1.1 for Finland, Germany and Latvia, respectively. Thus, the extent of the change to the lowest level is larger than the change to the highest level for Finland and Germany, while for Latvia the changes are of relatively equal size.

In Table 8, we compare the predicted number of visits under current conditions and the predicted number of visits under changed conditions for the four scenarios described

\footnotetext{
${ }^{6}$ Note, however, that the terms linear and non-linear here refer to the relative impacts of changes in the explanatory variables on the number of visits given that the estimated coefficients are half-elasticities. This implies that the absolute impact on the number of visits might differ even if the coefficients of a one-level and a two-level change are statistically not significantly different from one another.
} 


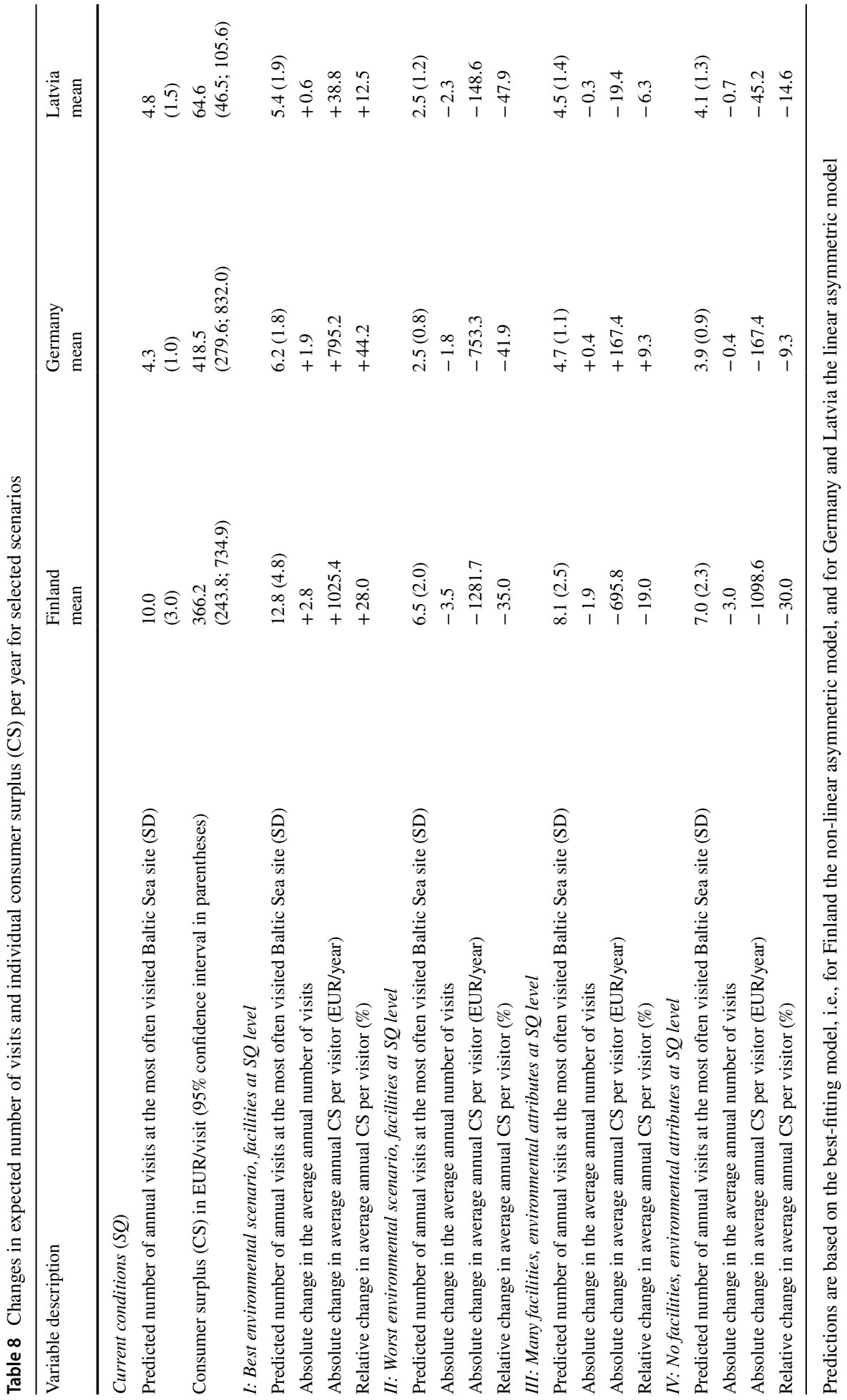


above. Changes in individual CS per year are calculated based on Eq. (5). ${ }^{7}$ For changes in the four environmental quality attributes (scenarios I and II), it can be observed that for Finland and Latvia, the expected number of visits reacts more strongly to environmental changes in the worst environmental scenario compared to the best environmental scenario. In the best environmental scenario, the expected number of visits to the most often visited Baltic Sea site would increase by 2.8 visits per year for Finland and by 0.6 visits per year for Latvia, while in the worst environmental scenario for these two countries, the expected number of visits would reduce by 3.5 and 2.3 visits per year, respectively. For the case of Germany, the expected number of visits would increase by 1.9 per year in the best environmental scenario and decrease by 1.8 visits per year in the worst scenario, although the average change from the SQ to the worst level is notably larger than the change to the best level. Overall, changes in facilities result in smaller effects on the number of visits (scenarios III and IV). Moving from the SQ level to either direction reduces the expected number of visits for Finnish and Latvian respondents, while German respondents would make more trips if the number of facilities increased and less if it decreased.

The changes in individual consumer surplus (CS) reflect these results. For the environmental scenarios (I and II), both absolute and relative changes in average annual CS per visitor are larger in the worst scenario than in the best scenario for the case of Finland and Latvia. In addition, this effect seemingly goes beyond asymmetries simply driven by the size of perceived changes when moving from the SQ to a policy scenario. In particular, for the case of Finland and Latvia, the extent of perceived improvements from the SQ to the best environmental scenario is quite similar to the extent of perceived deteriorations to the worst scenario. Still, changes in annual CS are notably larger in the worst environmental scenario than in the best scenario. For Germany, in contrast, the extent of perceived improvements in the best environmental scenario is much smaller than the extent of perceived deteriorations in the worst scenario. Still, relative changes in annual visitation numbers and CS are similar in both scenarios. For changes in facilities (scenarios III and IV), Finnish and Latvian respondents experience welfare losses from changes to a higher or lower level of facilities compared to the SQ, with a higher welfare effect resulting from a decrease in the number of facilities. For German respondents, having more facilities results in increased CS and having less in decreased CS, and the size of the effect is again independent of the direction of the change.

In all countries, the welfare effects of changes in the four environmental attributes (water clarity, blue-green algal blooms, algae onshore and bird diversity) are larger than the effect of changes in facilities. This is especially true for Germany, where changes in environmental attributes to the best or worst levels result in more than four times larger changes in CS than changes in facilities. Considering the effects of individual attributes (Table S6 in supplementary online material), deteriorations with respect to blue-green algal blooms result in the largest welfare effects for the case of Finland. For Germany and Latvia, in contrast, a decrease in water clarity causes the largest impacts on CS.

\footnotetext{
7 Note that we also tried a set of estimations in which we introduced interaction terms between the various environmental quality attributes and the travel cost variable. However, neither introducing the interaction terms one by one nor including them all together in the regressions resulted in significant parameters of the interaction terms. Consequently, the CS per visit is constant and does not vary depending on the realization of the environmental quality variables.
} 


\subsection{Aggregate Consumer Surplus}

Aggregate CS estimates related to changes in the marine environment are relevant for policy purposes, e.g., when estimating the economic benefits of achieving the objectives of European and Baltic Sea marine policies. To date, most policy-relevant benefit estimates are based on stated preference methods (Nieminen et al. 2019; Norton and Hynes 2018; Kosenius 2010; Ahtiainen et al. 2014). Results from TC and CB studies complement the existing information. While acknowledging that aggregation entails significant uncertainties as our sample is limited to those who have visited the Baltic Sea in the last 3 years, we provide aggregate welfare estimates for the three countries using the shares of non-users and assigning them zero values (Table 9). These aggregate estimates reflect the benefits and losses of those who currently visit the Baltic Sea and do not account for the possible benefits of people who are currently non-visitors but might start visiting the Baltic Sea if conditions improved. Thus, the estimates should be taken as indicative of the total value of changes in the Baltic Sea environmental conditions for Finland, Germany, and Latvia.

The aggregate CS estimates underline that the recreational use of the Baltic Sea yields considerable welfare for the citizens of the riparian countries based to a large extent on good environmental conditions. The aggregate CS estimates reflect the population size of the country but also take into account the share of non-users in the sample. Given the large population size, the current total annual CS for Germany amounts to 7276.6 billion EUR and is five times as large as the Finnish equivalent (1531.6 billion EUR), even though the share of non-users is pronouncedly larger in Germany than in Finland. Lower population

Table 9 Aggregate welfare estimates

\begin{tabular}{|c|c|c|c|}
\hline Variable description & Finland & Germany & Latvia \\
\hline \multicolumn{4}{|l|}{ Current conditions ( $S Q)$} \\
\hline Total annual consumer surplus (billion EUR) & 1531.6 & 7276.6 & 47.8 \\
\hline Population (number of people) & $5,503,000$ & $82,521,653$ & $1,950,116$ \\
\hline Share of non-users (\%) & 24 & 51 & 21 \\
\hline \multicolumn{4}{|l|}{ I: Best environmental scenario, facilities at $S Q$ level } \\
\hline Total consumer surplus (billion EUR) & 1960.4 & $10,491.8$ & 53.7 \\
\hline Absolute change in total consumer surplus (billion EUR) & +428.8 & +3125.2 & +6.0 \\
\hline Relative change in total consumer surplus (\%) & +28.0 & +44.2 & +12.5 \\
\hline \multicolumn{4}{|l|}{ II: Worst environmental scenario, facilities at $S Q$ level } \\
\hline Total consumer surplus (billion EUR) & 995.5 & 4230.6 & 24.9 \\
\hline Absolute change in total consumer surplus (billion EUR) & -536.0 & -3046.0 & -22.9 \\
\hline Relative change in total consumer surplus (\%) & -35.0 & -41.9 & -47.9 \\
\hline \multicolumn{4}{|l|}{ III: Many facilities, environmental attributes at $S Q$ level } \\
\hline Total consumer surplus (billion EUR) & 1240.6 & 7953.5 & 44.8 \\
\hline Absolute change in total consumer surplus (billion EUR) & -291.0 & +676.9 & -3.0 \\
\hline Relative change in total consumer surplus (\%) & -19.0 & +9.3 & -6.3 \\
\hline \multicolumn{4}{|l|}{$I V$ : No facilities, environmental attributes at $S Q$ level } \\
\hline Total consumer surplus (billion EUR) & 1072.1 & 6599.7 & 40.8 \\
\hline Absolute change in total consumer surplus (billion EUR) & -459.5 & -676.9 & -7.0 \\
\hline Relative change in total consumer surplus (\%) & -30.0 & -9.3 & -14.6 \\
\hline
\end{tabular}


size combined with lower individual CS per visit result in much lower but still considerable current total annual CS for Latvia (47.8 billion EUR). Reflecting the results presented in Sect. 4.3, the largest absolute and relative changes in total CS occur when environmental conditions obtain their best or worst levels (scenarios I and II), particularly for the case of Germany. The smallest absolute and relative effects on total CS can be observed when facilities change while environmental conditions remain at their SQ levels (scenarios III and IV), in particular for the case of Latvia.

\subsection{Robustness Checks and Comparison to Former Findings}

The econometric approach taken in this study did not explicitly account for the fact that respondents could also visit other sites as potential substitutes for their favorite Baltic Sea site. Rather, this was addressed in the framing of the CB questions by stating explicitly that environmental quality would only change at the most often visited site and the surrounding area and not in the remaining Baltic Sea. We, therefore, ensure that conditions in the remaining Baltic Sea are kept constant and avoid having to make unrealistic assumptions when calculating the welfare estimates. Moreover, we asked respondents not only how often they visited their favorite Baltic Sea site but also the Baltic Sea in general. The number of respondents who report the same number of visits to their most often visited site and to the Baltic Sea in general is relatively low for Finland (425 respondents, i.e., $42 \%$ of the total sample) and Latvia [305 respondents (58\%)] but considerable for Germany [403 respondents (70\%)]. We have included a linear asymmetric regression for these subsamples in the supplementary online material (Table S1) to check the robustness of our main results. The results show a similar pattern to the results for the full sample even though a few effects are no longer significant in the reduced sample. The magnitudes and signs of the coefficients, however, seem to be quite robust to reducing the sample.

We carried out two further robustness checks to look at the effects of weighting travel costs according to the purpose of the trip. Table S2 in the supplementary online material shows a linear asymmetric regression in which we only include the subsample of respondents who have visited no other than their single favorite site over the last 3 years. Table S3 shows a linear asymmetric regression for the full sample but with an alternative weighting scheme, putting substantially more weight on those visits for which recreation is the only or main purpose of the trip and substantially less weight on those visits for which recreation was only a minor purpose. The travel cost weights assigned in this alternative specification are $100 \%$ (only purpose), $75 \%, 5 \%, 3 \%$, and $1 \%$ (only a small purpose). The results for the reduced sample differ slightly to our main regressions which can be expected due to the substantially reduced sample sizes in the three countries. However, the results of the main regressions are very robust regarding a change in the weighting scheme.

Comparing our results to former studies is difficult since no studies using the same methods for valuing Baltic Sea recreational benefits are available. Czajkowski et al. (2015) used the TC approach to calculate the recreation benefits provided by the Baltic Sea for all riparian countries. The CS per visit is reported to be 80.7 Euros/visit for Finland, 77.6 Euros/visit for Germany, and 28.3 Euros/visit for Latvia, which is much lower than our estimates (366 Euros/visit for the Finnish sample, 419 Euros/visit for the German sample, and 65 Euros/ visit for the Latvian sample). However, Czajkowski et al. (2015) use a zero-inflated negative binomial model including users and non-users of the Baltic Sea coast in the estimation sample while we only include those respondents who had visited the Baltic Sea coast at least once over the last 3 years. This is reflected by the fact that the estimation samples in 
Czajkowski et al. (2015) show, on average, much lower numbers of reported trips, larger distances, and larger travel costs, both with and without opportunity costs of time.

Still, we carried out a further robustness check and fitted a symmetric travel cost model to our user samples in the three countries. For this regression, we neglected the information from the CB scenarios and only used the information on the actual trip. Accordingly, no panel model was necessary and a simple negative binomial model was used. In addition, we did not distinguish between improvements and deteriorations. This led to the following CS estimates: 93 Euros/visit for the Finnish sample, 196 Euros/visit for the German sample, and 37 Euros/visit for the Latvian sample (for a full set of estimation results, see Table S5 in the supplementary online material). These are still larger values than the estimates reported by Czajkowski et al. (2015). However, the authors also report that, on average, $55 \%$ of their respondents had taken no trips to the Baltic Sea. In our case, the share of non-users in the original sample, which we did not include in the estimations, amounts to 24\% for Finland, 51\% for Germany, and 21\% for Latvia.

Lankia et al. (2019) used the CB method to value changes in water quality as we do but there are several differences to our study. Firstly, they focus on Finland only. Secondly, they focus on swimming trips and do not include other forms of recreational activities. Thirdly, they include all water bodies including freshwater lakes and rivers, which are scattered throughout the country and cover $10 \%$ of Finland's surface area. This results in a much larger number of reported trips, smaller distances, and smaller travel costs, both with and without opportunity costs of time. Consequently, the CS estimates they report are substantially smaller than ours, amounting to 16 Euros/visit for respondents that go by car and 7 Euros/visit for respondents who walk or go by bike.

\section{Discussion and Conclusions}

This paper presents results of a CB study on the value of coastal and marine recreation for three Baltic Sea riparian countries, i.e., Finland, Germany, and Latvia, under changing environmental conditions. We describe the marine environment using five attributes: water clarity, blue-green algal blooms, algae onshore, biodiversity, and facilities. Moreover, we allow for asymmetric effects of quality improvements and deteriorations and contrast findings based on linear and non-linear regression models. The findings show that environmental conditions are a significant determinant of the number of recreation visits, and that deteriorations and improvements in water quality lead to different welfare effects. This indicates the presence of asymmetric preferences for marine water quality changes.

In particular, for some attributes and countries, we find asymmetries in the effects of improvements and deteriorations in the environmental attributes on the number of visits and consumer surplus. The results indicate that deteriorations lead to larger or more significant impacts in the case of blue-green algal blooms and algae onshore for Finland, water clarity for Germany, and water clarity and blue-green algal blooms for Latvia. In addition, the expected number of visits reacts more strongly to environmental conditions deteriorating to a worst environmental scenario compared to a best environmental scenario for the Finnish and Latvian respondents (Table 8). This carries over to changes in average annual CS per visitor: the losses incurred in the worst environmental scenario are larger than the gains in the best environmental scenario in these two countries. These results still hold when the size of the change in the two scenarios is taken into account. However, this does not carry over to the case of Germany, for which welfare changes in the best and worst 
environmental scenarios are of the same magnitude although the change from the SQ to the worst level is much larger.

However, our paper does not show a consistent picture of whether the number of visits would react more strongly to deteriorations than to improvements in the environmental conditions. For the attributes water clarity and bird diversity for Finland, as well as for the attributes blue-green algal blooms and algae onshore for Germany, it can be observed that the relative impact of improvements in environmental conditions on the number of visits is larger than the relative impact of deteriorations. This is in contrast to findings by Ahtiainen et al. (2015) who observed larger decreases in utility when water quality conditions deteriorated than increases in utility when they improved from an individual SQ among Finnish summer house owners. Such findings would be in line with prospect theory as postulated by Tversky and Kahneman (1991) and Kahneman and Tversky (1979). According to prospect theory, gains and losses are defined relative to a reference point, losses are valued more highly than corresponding gains, and marginal utility is decreasing.

One potential explanation for the inconsistent picture drawn by our results could be the fact that we cannot fully control for the reference point, i.e., the individual SQ, in our regressions. Given that improvements in environmental conditions were more likely to be presented to respondents in a worse SQ and deteriorations were more likely to be presented to respondents in a better SQ, the effects might in part reflect the different positioning on the utility curve, i.e., decreasing marginal utility. Based on these assumptions one would expect that respondents further up on the utility curve would react less strongly to the same change in environmental conditions than respondents further down on the utility curve. One would thus expect a tendency to observe that the impacts of deteriorations are less strong than the impacts of improvements (positioning effect). This effect would counteract the expectation to observe stronger reactions to deteriorating conditions than to improving conditions based on loss aversion (loss aversion effect).

Fully taking this into account would require including a large number of interaction terms for the SQ and the quality levels in the regressions, which would result in models that are too extensive to yield sensible results. However, keeping the counteracting effects in mind, we can be confident that for the cases in which the estimated coefficients are larger for deteriorations than for improvements, the number of visits in fact reacts more strongly to deteriorations than to improvements because the loss aversion effect dominates the positioning effect. This holds in the case of blue-green algal blooms and algae onshore for Finland, water clarity for Germany, and water clarity and blue-green algal blooms for Latvia. These are notably the attributes which are of particular importance for recreationists at the Baltic Sea. For the cases in which the estimated coefficients are smaller for deteriorations than for improvements, in contrast, we cannot draw unambiguous conclusions.

Regarding the spatial accuracy of the reported sites, we used specific survey software (Maptionnaire) with an integrated mapping tool for collecting the survey data for this paper. This allowed us to elicit spatially precise information on the places of residence and the recreation sites of the respondents. Compared to the commonly used approach to use, e.g., postal codes as a proxy for locating places of residence and recreation sites, this should provide us with higher quality spatial information underlying the CB analysis. Merging this spatial data with information on the sizes, shapes, coastline formations, and population densities of the three countries allows us to draw conclusions on how these aspects influence recreational behavior. For example, as the German Baltic Sea coastline is rather short and the country stretches further away from the Baltic Sea than the other countries, the German sample contains much more tourists (i.e., respondents who live more than $30 \mathrm{~km}$ away from the Baltic Sea and stayed more than $12 \mathrm{~h}$ at the site) than the 
Finnish and Latvian samples, which predominantly consist of people visiting the Baltic Sea for shorter recreation trips.

In the analysis, all Baltic Sea recreation sites are pooled to a single site, and the estimations are based on individual-specific reference (SQ) conditions defined by the respondent. These are then compared to hypothetical environmental conditions for five environmental attributes in the CB scenarios. Combining a pooled CB model for several quality attributes with the application of an individual SQ and allowing for asymmetric preferences is a novel extension of valuation techniques in a revealed preference setting and has, in particular, not been used in the context of Baltic Sea recreation before. Thus, the paper illustrates an approach of conducting a CB study, which can be particularly useful when national benefit estimates are needed and there are many heterogeneous sites which differ in environmental quality.

The results on the perception of the SQ conditions at the most often visited Baltic Sea sites seem to reflect that the overall water quality along the Baltic Sea coast as perceived by the visitors is relatively good even though there are pronounced differences among the countries. Of course this raises the question of whether such perceptions reflect actual environmental conditions, i.e., physical or bio-geochemical conditions as measured by naturalscientific methods. However, there is evidence that the correlation between perceived and physically measured conditions is significant and positive, even though respondents tend to perceive environmental conditions to be better than objective ones especially when objective water quality assessments state poor conditions (Artell et al. 2013). Moreover, perceptions matter for individual decision-making and are thus central for evaluating impacts of environmental changes (Adamowicz et al. 1997). Taken together, the observations on the perceptions of environmental quality at the most often visited Baltic Sea sites support the usage of the CB method applied in this paper because this method is able to capture the effects of environmental changes that go beyond observed levels. This would have been a limitation of using the TC method for valuing recreational benefits in a case where perceived environmental conditions are relatively uniformly distributed and do not include rather poor water qualities.

Comparing our results to former studies, as far as this is possible, we find that the CS estimates in Euros per visit calculated based on the full-sample negative binomial CB model are comparably large. Fitting a simple TC model and accounting for non-users would produce results that are more comparable with estimates from Czajkowski et al. (2015) but still much larger than estimates in Lankia et al. (2019). One reason for this could be the different degree of substitutability. Recreational visits to the Baltic Sea may be perceived by respondents to be much more unique, on average, than swimming trips to all available water bodies, i.e., including fresh water lakes and rivers. Particularly for the case of Germany, the Baltic Sea coast is quite small and distances to the Baltic Sea are quite large for the average population. But also for the case of Finland, where the Baltic Sea coast is much longer, only $20 \%$ of the respondents typically swim in the Sea (Lankia et al. 2019) such that visits to the Baltic Sea may be considered more unique than visits to a water body in general. Estimating CS per visit may thus result in larger CS estimates if only Baltic Sea recreation is considered while CS estimates are smaller when recreational visits to all water bodies are included. Another reason for differing CS estimates per visit could also be differences in the duration of the stay. Unfortunately, neither Lankia et al. (2019) nor Czajkowski et al. (2015) report the average duration of a visit.

Still, there remains a substantial difference in our CS estimates if we compare the results based on a simple TC approach using a negative binomial model to results based 
on the CB approach using a random-effects negative binomial model. The same effect, i.e., that respondents seem to be less sensitive to TCs when assessing future visits, has been observed by Rolfe and Dyack (2011). They hypothesize that it could be due to the fact that respondents could not adjust both trip rates and TCs in the hypothetical scenarios or that it could just be an artificial consequence of the data stacking process of combining revealed and stated preference data. Alberini et al. (2007), in contrast, do not find substantial differences in the TC coefficient depending on whether they use a simple TC model or a CB model. They also do not find an effect on the TC coefficient regardless of whether just environmental conditions or also TCs change in the hypothetical scenarios. However, they use ordinary least squares regressions so that the findings may not be transferable.

Overall, it might be that we tend to overestimate the recreational benefits of Baltic Sea coastal recreation given that the CS estimates are larger in the CB model than in the simple TC model. It remains to be shown by future research to what extent the CB approach is prone to a hypothetical bias or to find a different answer for the puzzle of the differing CS estimates.

The findings of our study illustrate the substantial value of coastal and marine recreation, as well as how these values change when environmental conditions in marine areas change. This information is relevant for the implementation of national and regional marine policies, including the HELCOM Baltic Sea Action Plan and the EU MSFD, which both aim at reaching a good environmental status of marine waters. The MSFD requires economic and social analyses of the use of marine waters, cost of degradation and the benefits of new measures to improve the state of the marine environment. We provide estimates of the value of recreation under current conditions as one of the current uses of marine waters, and also allow estimating the costs of degradation for recreation if the marine environment deteriorates. The findings can also be used to assess the welfare impacts of measures that improve environmental conditions for recreational benefits. In addition, the results can be used to support marine spatial planning, as they show recreation locations along the Baltic Sea coast and allow for determining the value of marine recreation.

Acknowledgements Open Access funding provided by Projekt DEAL. This work resulted from the BONUS BALTICAPP project and was supported by BONUS (Art 185), funded jointly by the EU, the Academy of Finland and the Federal Ministry of Education and Research in Germany. We thank two anonymous reviewers, the Co-Editor, participants of the WCERE 2018 in Gothenburg, and participants of the $3^{\text {rd }}$ BONUS Symposium 2018 in Gdansk for valuable comments on an earlier draft of the paper.

Open Access This article is licensed under a Creative Commons Attribution 4.0 International License, which permits use, sharing, adaptation, distribution and reproduction in any medium or format, as long as you give appropriate credit to the original author(s) and the source, provide a link to the Creative Commons licence, and indicate if changes were made. The images or other third party material in this article are included in the article's Creative Commons licence, unless indicated otherwise in a credit line to the material. If material is not included in the article's Creative Commons licence and your intended use is not permitted by statutory regulation or exceeds the permitted use, you will need to obtain permission directly from the copyright holder. To view a copy of this licence, visit http://creativecommons.org/licenses/by/4.0/.

\section{Appendix}

See Table 10 . 


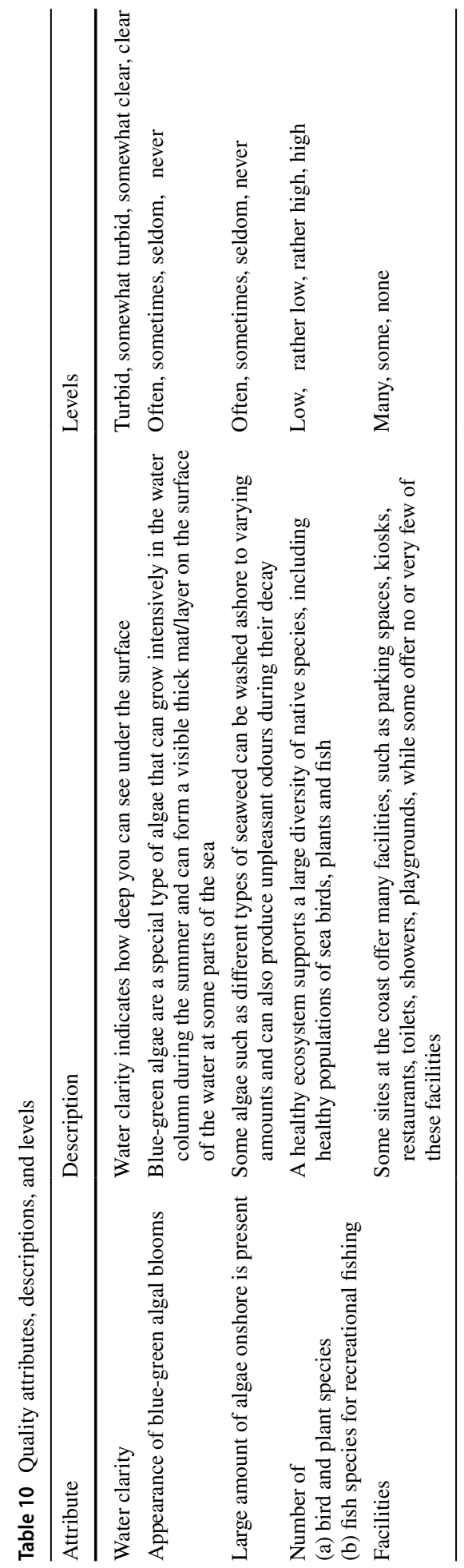




\section{References}

Adamowicz V, Swait J, Boxall P, Louviere J, Williams M (1997) Perceptions versus objective measures of environmental quality in combined revealed and stated preference models of environmental valuation. J Environ Econ Manage 32:65-84

Ahtiainen H, Artell J, Czajkowski M, Hasler B, Hasselström L, Hyytiäinen K, Meyerhoff J, Smart JC, Söderqvist T, Zimmer K, Khaleeva J (2013) Public preferences regarding use and condition of the Baltic Sea-an international comparison informing marine policy. Mar Policy 42:20-30

Ahtiainen H, Artell J, Czajkowski M, Hasler B, Hasselström L, Huhtala A, Meyerhoff J, Smart JC, Söderqvist T, Alemu MH, Angeli D (2014) Benefits of meeting nutrient reduction targets for the Baltic Sea-a contingent valuation study in the nine coastal states. J Environ Econ Policy 3(3):278-305

Ahtiainen H, Pouta E, Artell J (2015) Modelling asymmetric preferences for water quality in choice experiments with individual-specific status quo alternatives. Water Resour Econ 12:1-13

Alberini A, Zanatta V, Rosato P (2007) Combining actual and contingent behavior to estimate the value of sport fishing in the Lagoon of Venice. Ecol Econ 61(2-3):530-541

Artell J, Ahtiainen H, Pouta E (2013) Subjective versus objective measure in the valuation of water quality. J Environ Manage 130:288-296

Banzhaf MR, Johnson FR, Mathews KE (2001) Opt-out alternatives and anglers' stated preferences. In: Bennett J, Blamey R (eds) The choice modelling approach to environmental valuation. Edward Elgar, London, pp 157-177

Baranzini A, Schaerer C, Thalmann P (2010) Using measured instead of perceived noise in hedonic models. Transp Res Part D 15:473482

Barry L, van Rensburg TM, Hynes S (2011) Improving the recreational value of Ireland's coastal resources: a contingent behavior application. Mar Policy 35:764-771

Barton D, Bergland O (2010) Valuing irrigation water using a choice experiment: an 'individual status quo' modelling of farm specific water scarcity. Environ Dev Econ 15(3):321-340

Bertram C, Rehdanz K (2013) On the environmental effectiveness of the EU marine strategy framework directive. Mar Policy 38:25-40

Bhat MG (2003) Application of non-market valuation to the Florida keys marine reserve management. J Environ Manage 67(4):315-325

Birol E, Villalba ER, Smale M (2009) Farmer preferences for milpa diversity and genetically modified maize in Mexico: a latent class approach. Environ Dev Econ 14(4):521-540

Blayac T, Hamadé F, Sales J (2016) Valuing the rescreation of a marine and terrestrial nature protected area: a travel cost analysis of Port-Cros national park. Revue d'économie politique 126:127-153

Bockstael N, Hanemann WM, Strand I (1984) Measuring the benefits of water quality improvements using recreational demand models. Environmental Protection Agency, Washington, DC

Cameron AC, Trivedi PK (2013) Regression analysis of count data, 2nd edn. Cambridge University Press, New York

Christie M, Hanley N, Hynes S (2007) Valuing enhancements to forest recreation using choice experiment and contingent behaviour methods. J For Econ 13:75-102

Czajkowski M, Ahtiainen H, Artell J, Budzínski W, Hasler B, Hasselström L, Meyerhoff J, Nõmann T, Semeniene D, Söderqvist T, Tuhkanen H, Lankia T, Vanags A, Zandersen M, Żylicz T, Hanley N (2015) Valuing the commons: an international study on the recreational benefits of the Baltic Sea. J Environ Manage 156:209-2017

Domínguez-Torreiro M, Soliño M (2011) Provided and perceived status quo in choice experiments: implications for valuing the outputs of multifunctional rural areas. Ecol Econ 70(12):2523-2531

du Preez M, Hosking S (2011) The value of the trout fishery at Rhodes, North Eastern Cape, South Africa: a travel cost analysis using count data models. J Environ Plan Manage 54:267-282

Egan K, Herriges J (2006) Multivariate count data regression models with individual panel data from an onsite sample. J Environ Econ Manage 52:567-581

Eiswerth ME, Englin J, Fadali E, Shaw WD (2000) The value of water levels in water-based recreation: a pooled revealed preference/contingent behavior model. Water Resour Res 36(4):1079-1086

Englin J, Cameron TA (1996) Augmenting travel cost models with contingent behavior data. Environ Resource Econ 7(2):133-147

EU (European Union, 2008) Directive 2008/56/EC of the European Parliament and of the Council of 17 June 2008 establishing a framework for community action in the field of marine environmental policy (Marine Strategy Framework Directive). Strasbourg, France

Eurostat (2017) Purchasing power parities (PPPs), price level indices and real expenditures for ESA 2010 aggregates. Eurostat database. http://appsso.eurostat.ec.europa.eu/nui/show.do?dataset=prc ppp_ind\&lang=en. Last updated 29 June 2017, Accessed 5 Oct 2017 
Glenk K (2011) Using local knowledge to model asymmetric preference formulation in willingness to pay for environmental services. J Environ Manage 92(3):531-541

Hanley N, Bell D, Alvarez-Farizo B (2003) Valuing the benefits of coastal water quality improvements using contingent and real behavior. Environ Resource Econ 24(3):273-285

HELCOM (2018) Helcom Map and Data Service, http://www.helcom.fi/baltic-sea-trends/data-maps/. Accessed 21 June 2018

Hess S, Rose JM, Hensher DA (2008) Asymmetric preference formation in willingness to pay estimates in discrete choice models. Transp Res Part E 44(5):847-863

Hynes S, Greene W (2013) A panel travel cost model accounting for endogenous stratification and truncation: a latent class approach. Land Econ 89(1):177-192

Jeon Y, Herriges JA, Kling CL, Downing J (2005) The role of water quality perceptions in modeling lake recreation demand. Iowa State University, Department of Economics. Working Paper 05032

Kahneman D, Tversky A (1979) Prospect theory: an analysis of decision under risk. Econometrica 47(2):263-291

Kataria M, Bateman I, Christensen T, Dubgaard A, Hasler B, Hime S, Ladenburg J, Levin G, Martinsen L, Nissen C (2012) Scenario realism and welfare estimates in choice experiments-a non-market valuation study on the European water framework directive. J Environ Manage 94(1):25-33

Kosenius AK (2010) Heterogeneous preferences for water quality attributes: the case of eutrophication in the Gulf of Finland, the Baltic Sea. Ecol Econ 69(3):528-538

Kragt ME, Roebeling PC, Ruijs A (2009) Effects of Great Barrier Reef degradation on recreational reeftrip demand: a contingent behavior approach. Aust J Agric Resour Econ 53:213-229

Lankia T, Neuvonen M, Pouta E (2019) Effects of water quality changes on the recreation benefits of swimming in Finland: combined travel cost and contingent behavior model. Water Resour Econ 25:2-12. https://doi.org/10.1016/j.wre.2017.10.002

Lanz B, Provins A, Bateman IJ, Scarpa R, Willis K, Ozdemiroglu E (2010) Investigating willingness to pay-willingness to accept asymmetry in choice experiments. In Hess S, Daly A (Eds) 2010. Choice modelling: the state-of-the-art and the state-of-practice-of proceedings from the inaugural international choice modelling conference, pp 517-542. Emerald Group Publishing Limited, Bingley, UK

Luisetti T, Bateman IJ, Turner RK (2011) Testing the fundamental assumption of choice experiments: Are values absolute ore relative? Land Econ 87(2):284-296

Marsh D, Mkawa L, Scarpa R (2011) Do respondents' perceptions of the status quo matter in non-market valuation with choice experiments? An application to New Zealand freshwater streams. Sustainability 3:1593-1615

Martínez-Espiñeira R, Amoako-Tuffour J (2009) Multi-destination and multi-purpose trip effects in the analysis of the demand for trips to a remote recreational site. Environ Manage 43:1146-1161

Masiero L, Hensher DA (2010) Analyzing loss aversion and diminishing sensitivity in a freight transport choice experiment. Transp Res Part A 44(5):349-358

Nieminen E, Ahtiainen H, Lagerkvist CJ, Oinonen S (2019) The economic benefits of achieving Good Environmental Status in the Finnish marine waters of the Baltic Sea. Mar Policy 99:181-189

Norton D, Hynes S (2018) Estimating the benefits of the Marine Strategy Framework Directive in Atlantic Member States: a spatial value transfer approach. Ecol Econ 150:82-94

OECD (2018) Hours worked: average annual hours actually worked, OECD Employment and Labour Market Statistics (database), https://doi.org/10.1787/data-00303-en. Accessed 21 June 2018

Pakalniete K, Aigars J, Czajkowski M, Strake S, Zawojska E, Hanley N (2017) Understanding the distribution of economic benefits from improving coastal and marine ecosystems. Sci Total Environ 584:29-40

Rolfe J, Dyack B (2011) Valuing recreation in the Coorong, Australia, with travel cost and contingent behavior models. Econ Rec 87(277):282-293

Sagebiel J, Schwartz C, Rhozyel M, Rajmis S, Hirschfeld J (2016) Economic valuation of Baltic marine ecosystem services: blind spots and limited consistency. ICES J Mar Sci 73(4):991-1003

Söderqvist T, Eggert H, Olsson B, Soutukorva A (2005) Economic valuation for sustainable development in the Swedish coastal zone. AMBIO J Hum Environ 34(2):169-175

Soutukorva A (2005) The value of improved water quality - a random utility model of recreation in the Stockholm Archipelago. Sustainable Coastal Zone Management Programme, project 1.2.1, subproject on benefits, Stockholm, Sweden 
Tversky A, Kahneman D (1991) Loss aversion in riskless choice: a reference-dependent model. Q J Econ 106(4):1039-1061

Vesterinen J, Pouta E, Huhtala A, Neuvonen M (2010) Impacts of changes in water quality on recreation behavior and benefits in Finland. J Environ Manage 91:984-994

Publisher's Note Springer Nature remains neutral with regard to jurisdictional claims in published maps and institutional affiliations. 